\title{
SUBSURFACE BARRIER INTEGRITY VERIFICATION USING PERFLUOROCARBON TRACERS
}

\author{
Letter Report
}

T.M. Sullivan
J. Heiser
L. Milian
G. Senum

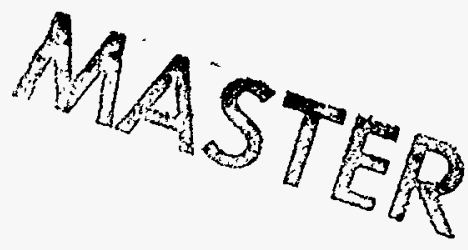

December 1996

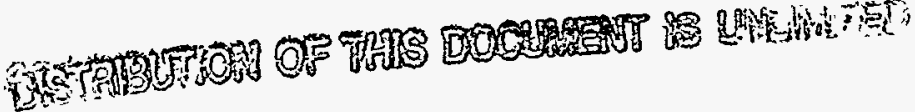

Prepared by:

Environmental \& Waste Technology Center

Department of Advanced Technology

Brookhaven National Laboratory

Upton, NY 11953

Prepared for:

U.S. Department of Energy Office of Science \& Technology

Contract No. DE-AC02-76CH00016 


\section{DISCLAIMER}

Portions of this document may be illegible in electronic image products. Images are produced from the best available original document. 


\section{DISCLAIMER}

This report was prepared as an account of work sponsored by an agency of the United States Government. Neither the United States Government nor any agency thereof, nor any of their employees, make any warranty, express or implied, or assumes any legal liability or responsibility for the accuracy, completeness, or usefulness of any information, apparatus, product, or process disclosed, or represents that its use would not infringe privately owned rights. Reference herein to any specific commercial product, process, or service by trade name, trademark, manufacturer, or otherwise does not necessarily constitute or imply its endorsement, recommendation, or favoring by the United States Government or any agency thereof. The views and opinions of authors expressed herein do not necessarily state or reflect those of the United States Government or any agency thereof. 


\section{SUBSURFACE BARRIER INTEGRITY VERIFICATION USING PERFLUOROCARBON TRACERS}

T. M. Sullivan, J. Heiser, L. Milian and G. Senum

\section{INTRODUCTION}

Subsurface barriers are an extremely promising remediation option to many waste management problems. Potential uses of subsurface barriers include surrounding and containing buried waste, as secondary confinement for underground storage tanks, to direct or contain subsurface contaminant plumes, and to restrict remediation methods, such as vacuum extraction, to a limited area. Subsurface barriers are a remediation option for many of the Department of Energy sites including: Brookhaven National Laboratory, Sandia National Laboratory, Idaho National Engineering Laboratory, Oak Ridge National Laboratory, Hanford, Fernald, and Rocky Flats. Barriers are also considered an important remediation option by the U.S. Environmental Protection Agency [Siskind and Heiser, 1993].

The ability to verify barrier integrity through monitoring will be required to gain public acceptance of subsurface barriers as either a primary or secondary means of confinement of wastes. To effectively contain the wastes, the barriers should be continuous and have few or no breaches. Currently, no placement technology can guarantee the completeness of the engineered 
barrier. A breach may be formed by many processes including: discontinuous grout application, joint formation between grout panels, cracking during curing, localized "tears" due to differential settling, wet/dry cycling, and, over time, degradation of the grout due to chemical attack.

The large size and deep placement of subsurface barriers makes demonstration of barrier integrity a challenging task. This becomes magnified if the permissible leakage from the site is low. Several geophysical techniques exist for the determination of barrier physical properties. These include the four major types of measurement techniques: nuclear, electrical, acoustic, and thermal as well as tracer technologies. A detailed review of the applicability of all of these techniques can be found in [Heiser, 1994]. In general, geophysical techniques are able to monitor properties of the barrier such as porosity, density, and moisture content. They may also useful in determining the location of the barrier in the subsurface. However, they are not able to detect small fractures (a few centimeters in size). Gas tracer technology is believed to provide the best method for monitoring and verifying barrier performance in the unsaturated zone at this time.

Tracer techniques involve emplacement or injection of a substance that will migrate to a collection point. Based on the rate of arrival at the monitoring well and the transport properties of the tracer and materials in the subsurface system, estimates of barrier integrity can be obtained. For subsurface soil systems, the tracer can be radioactive or non-radioactive liquids or gases. Radioactive tracers can be incorporated into the barrier grout and the radiation field can 
be monitored to ascertain the location of the grout. In this case, the migrating substance is the radiation particle. For barrier integrity studies in the unsaturated zone, gas phase tracers are needed. Liquid phase tracers will not have high enough mobility to be useful for determining barrier integrity on a short time scale. Gas phase tracers show promise to be able to detect fractures on the order of a few centimeters in size.

Gas phase tracers include perfluorocarbon tracers (PFT's) and chlorofluorocarbon tracers (CFC's). Both have been applied for leak detection in subsurface systems. PFT's have been used to detect leaks in buried natural gas pipelines, the rate of dioxin movement into a commercial building from surrounding contaminated soil, the rate of leaking dielectric fluid from subsurface electrical cables, the rate of leaking gasoline from underground storage tanks and the rate of radon ingress into residential basements [D'Ottavio and Deitz 1987, Horn et. al., 1991].

In this study, PFT's were chosen as the tracer. PFT's have the following advantages and characteristics as compared to other tracers:

- Negligible background concentrations. Consequently, only small quantities are needed;

- PFT's are nontoxic, nonreactive, nonflammable, environmentally safe (does not contain chlorine) and commercially available;

- PFT technology is the most sensitive of all non-radioactive tracer technologies.

Concentrations in the range of 10 parts per quadrillion of air can be easily measured;

- PFT technology can simultaneously deploy, sample, and analyze up to six PFT's with the 
same instrumentation. This results in lower costs and flexibility in experimental design, testing and data interpretation.

- $\quad$ PFT concentrations can be analyzed in a few minutes in the field or in the laboratory using gas chromatography.

The ability to use multiple tracers at a single site can help to improve the spatial resolution of the breach. Theoretically, the combination of monitoring data with numerical modeling of the movement of the PFT's can be used to locate hole size down to a few centimeters in size. Field testing of the resolution that can be obtained in the field remains to be done.

The focus of this report is to describe the barrier verification tests conducted using PFT's and analysis of the data from the tests. Discussions of other techniques (i.e. excavation) to demonstrate barrier integrity are provided elsewhere (Dwyer, 1996). PFT verification tests have been performed on a simulated waste pit at the Hanford Geotechnical facility and on an actual waste pit at Brookhaven National Laboratory (BNL). The objective of these tests were to demonstrate the proof-of-concept that PFT technology can be used to determine if small breaches form in the barrier and for estimating the effectiveness of the barrier in preventing migration of the gas tracer to the monitoring wells. The next section describes the subsurface barrier systems created at Hanford and BNL. The experimental results and the analysis of the data follows. Based on the findings of this study, conclusions are offered and suggestions for future work are presented. 


\section{EXPERIMENTAL SYSTEMS}

\subsection{Hanford Geotechnical Test Facility}

Testing was performed at the Hanford Geotechnical Test Facility which has been in existence since 1982. It was developed to obtain information on low-level waste subsurface burial subsidence control alternatives. Over the years, this facility has been used in numerous subsurface testing programs. In this study, a low-permeability barrier was emplaced around and beneath a simulated waste tank without disturbing the waste tank. The containment structure is a multi-barrier comprised of a cementitious grout lined with a polymer grout. The system design called for the two grouts to be emplaced in a close-coupled fashion such that the polymer barrier is bonded to the cementitious barrier.

The demonstration of barrier integrity was conducted in two parts. In the first phase, the PFT perfluoromethylcylohexane, $\mathrm{PMCH}$, was injected into the system beneath the center of the simulated waste tank approximately three meters below grade prior to emplacement of the polymer grout.

During the first phase of the program, prior to installation of the cementitious grout liner monitoring wells were installed. The monitoring network consisted of seven wells located parallel to and approximately one meter outside the cement grout barrier. These wells were used to draw samples to measure the PFT concentration as a function of time. These wells are 
designated by their location as North, Northeast, East, Southeast, South, Southwest, and Northwest. An eight well, located in the West position, failed possibly due to plugging of the well screens. These wells were composed of perforated casing. Two wells were located in the interior of the cemented region. These wells are designated North and South and are located parallel to and one meter inside the barrier. These wells were used to measure the concentrations during the injection period of three days.

The injection started on October 18 and lasted for three days at a nominal rate of 15 $\mathrm{cm}^{3} / \mathrm{min}$ (measured rates varied between $12-15 \mathrm{~cm}^{3} / \mathrm{min}$ ) at a PMCH concentration of $373 \mathrm{ppm}$. In the seven external monitoring wells, tracer concentration measurements were performed at the end of the injection period and beginning with the sixth day after the start of injection, measurements were made daily except on weekends for 17 days. The data is reproduced in Appendix A. This data permits evaluation of the cement grout as a barrier to release and allows estimation of transport parameters in native soil and the cement grout.

After completing the tests and analyzing the data, the polymer grout was injected in December of 1995. In March of 1996, another PFT, ortho-cis-perfluorodimethylcyclohexane, ocPDCH, was injected into the subsurface at the center of the simulated waste tank as before. The injection started on March 3 and lasted for three days at a nominal rate of $15 \mathrm{~cm}^{3} / \mathrm{min}$ at an ocPDCH concentration of $30 \mathrm{ppm}$. In this case, the monitoring wells were constructed to permit sampling at different depths by inserting copper tubing of different lengths inside the well casing. This is discussed further in Section 3.3.2.1. 
The physical system at Hanford which is under study is displayed in Figure 1. The approximate dimensions of the system are $6.3 \mathrm{~m}$ deep and $12.5 \mathrm{~m}$ in diameter. The cementitious barrier wall was constructed by injecting two parallel rows of grout at an angle of $\pi / 4$ radians ( 45

degrees) to the ground surface. Figure 2 shows the equipment used to inject the grout. A schematic of the top view of the system is displayed in Figure 3. In this study, the barrier was covered by $60 \mathrm{~cm}$ of soil. The use of a sloping barrier wall forms an inverted cone. The second row of the barrier is used to increase the thickness of the grout barrier and help insure that large scale breaches in the barrier do not occur. The design basis thickness of the cementitious grout barrier is one meter (this is the thickness in the plane parallel to the barrier).. Figure 4 shows the monitoring wells and the extension of the tank above the ground surface. The tank represents a simulated waste form and has dimensions of approximately $3 \mathrm{~m}$ in diameter and $2.4 \mathrm{~m}$ in height.

\section{$2.2 \quad$ BNL Glass Pit}

Past disposal practices at Brookhaven National Laboratory involved excavating a cylindrical pit with a diameter of $10-15$ feet and a depth of 5-20 feet. Approximately 20 such pits exist. Routine waste disposal in these pits included glass bottles of chemical solvents, acids, bases, and other liquid wastes. Currently, many of the bottles are intact and partially filled. The water table is between 10 and 20 feet beneath the glass pits in this area at BNL. Thus, there is a concern that these bottles will leak at some time in the future and cause a groundwater contamination problem. 
One glass pit wás selected for use as a demonstration of subsurface barrier technology. Jet grouting was used to emplace a cementitious subsurface barrier around the glass pit. As in the Hanford barrier experiment, the cement layer was lined with an acrylic polymer to increase barrier performance. The waste containing region near the center of the pit was solidified using a cementitious grout. The geometry of the barrier placed around the waste is displayed in Figure 5. The barrier was a trough with vertical end walls and side walls angled at $\pi / 4$ radians ( 45 degrees) meeting at the centerline of the trough underneath the wastes. The approximate dimensions of this site is 50 feet along the vertical walls and 30 feet on the angled walls. During grouting of the waste containing region of the pit, the PFT ocPDCH was injected in the interior of the subsurface barrier. Injection proceeded for approximately 1 day at a concentration of $30 \mathrm{ppm}$. The nominal air injection rate was $15 \mathrm{~cm}^{3} / \mathrm{min}$. The injection was stopped when the region surrounding the injection point was solidified in the grout. Data was collected at four interior and ten exterior wells. The injection location and the location of all interior and exterior wells is marked on Figure 6. Monitoring points labeled as 45 degree holes indicate that the well holes are parallel to the sloping face of the subsurface barrier and approximately equidistant from the barrier at all points. Wells on the sides labeled North and South are vertical and parallel to the subsurface barrier. Exterior wells were designed to collect data at five foot intervals to provide spatial resolution of the gas tracer plume.

\subsection{DATA COLLECTION AND INTERPRETATION}

To support the PFT testing procedure, modeling of the subsurface movement of the PFT 
gas has been conducted for the Hanford soil/neat cement barrier. The modeling will be used to estimate the rate at which the tracer will travel through the barrier and reach the monitoring wells, to demonstrate the effects of small holes $(1-10 \mathrm{~cm})$ on concentration at the well, and the effects of the waste tank on movement of the gas. This modeling information was used to assist in the determination of injection rates for PFT's into the subsurface system, the frequency and duration of sampling, and the time to flush the system prior to testing the close-coupled system.

\subsection{Conceptual Model}

The problem involves transport of an injected gas tracer through an engineered barrier (soil/neat cement) to a monitoring well. To model this requires knowledge of the rate of tracer injection, location of injection, geometry of the system, location of the monitoring wells, and transport properties of the PFT through the soil and soil/neat cement barrier. The complicated geometry (e.g. sloping walls, potential for flow through a small hole, and simulated tank) and the non-uniform transport regions, i.e., the soil and the barrier, necessitate a numerical solution.

The diffusion equation with a time-dependent external source is used to solve for the movement of the tracer from the injection location throughout the modeled domain. The equation is:

$$
\frac{\partial C}{\partial t}=D \nabla^{2} C(x, z, t)+Q(x, z, t)
$$

where: $\quad C(x, z, t)$ is the tracer concentration 
$D$ is the diffusion/dispersion coefficient $\left(\mathrm{cm}^{2} / \mathrm{s}\right)$, and

$Q(x, z, t)$ is the rate of tracer injection into the system.

The dominant transport process for air in soil systems is believed to be diffusion [Hillel, 1983]. Advection resulting from barometric pressure changes can facilitate the release of the tracers to the atmosphere and was considered in the initial phase of the modeling. The advection due to barometric pressure changes is expected to vary cyclically. These pressure changes will lead to times when the flow is into the soil and times when the flow is directed out of the soil. The preliminary modeling results indicated that for likely values of the cyclical advection velocity, diffusion would be the dominant transport process as expected and advection could be neglected [Sullivan et. al., 1996]. Substantial differences between the predicted concentrations of the diffusion only and the diffusion with cyclical advection case occurred only in the top meter of the soil. However, since the permeability of the soil was not measured, advection can not be completely ruled out as a transport mechanism.

The measured diffusion coefficient for the PFT PMCH in air is $5 \cdot 10^{-2} \mathrm{~cm}^{2} / \mathrm{s}$. Measured values in the soil system at the Hanford test facility are not available. To account for tortuosity effects in the soil, the diffusion coefficient of PMCH in the soil has been estimated as $10^{-2} \mathrm{~cm}^{2} / \mathrm{s}$ for the base case. This value is similar to that for radon gas in dry soils [Nielson and Rogers, 1982]. Radon and the PFT's are inert gases with approximately similar molecular weights (e.g. Radon molecular weight $=226$ and PMCH molecular weight $=350$ ). Therefore, the diffusion coefficients of the two gases should be similar. The diffusion coefficient through the soil/neat 
cement was selected as $10^{-4} \mathrm{~cm}^{2} / \mathrm{s}$. The range of diffusion coefficients for radon gas through residential concretes is $10^{-4}-5 \cdot 10^{-3} \mathrm{~cm}^{2} / \mathrm{s}$ [Rogers et. al., 1984]. A value from the low end of the range was selected in the initial stages of modeling in an attempt to provide a lower estimate of release to the monitoring wells and to insure that sampling would be able to detect the PFT's.

Simulations with a completely intact barrier were performed as a baseline. Then the effects of having small imperfections (caused by imperfect grouting) were studied. In this analysis, the imperfections are represented as a hole through the entire wall. The range of hole sizes that were modeled was between one and ten $\mathrm{cm}$.

\subsection{Computational Model for the Hanford Test Site}

At the Hanford test site the PFT's were injected into the center of the inverted cone directly beneath the waste tank. This permitted an assumption of cylindrical symmetry. Therefore, to simulate this physical system described in the previous section, Figure 1, a twodimensional cylindrical slice through the center of the cone was taken. The tank in Figure 1 was represented as a no flow boundary. For simplicity and because of the lack of site-specific data, it is assumed that there are two distinct materials in the subsurface system, the soil and the soil/neat cement barrier. The subsurface barrier system at the Hanford test facility was modeled in cylindrical geometry using a two-dimensional finite-element transport code, BLT [Sullivan and Suen, 1989]. 
This problem has two size scales. The first scale is that of the system itself. The height from the bottom of the subsurface barrier to the ground surface is $6.6 \mathrm{~m}$. The radius of the barrier was also approximately $6.6 \mathrm{~m}$ and a total distance of $12.8 \mathrm{~m}$ was simulated in the direction parallel to the ground surface. The second scale is that of the size of the potential breach which is on the order of a few centimeters. It would require nearly one million computational points to model the entire system on the scale of one centimeter. This is not computationally feasible. To account for the two scale sizes, variable mesh spacing was used. A fine mesh (order of one centimeter) was used in the region of the hypothetical breach. The mesh was increased in size as the distance away from the hypothetical breach increased. The slanting soil/neat cement barrier was modeled by defining the finite elements used to represent the barrier to also slant at a $\pi / 4$ radians ( 45 degree) angle. These two details led to a complicated finiteelement mesh with three thousand computational points, Figure 6.

Initially, the system is tracer free and, therefore, the initial condition is zero concentration at all locations. The boundary condition assumed zero flux at the centerline due to the assumed symmetry. Zero concentration boundary conditions were used at the top boundary, bottom boundary, and right-hand boundary defined in Figure 6 . The right-hand boundary is located at a large enough distance such that the tracer does not reach the boundary during the simulation period of 0.1 years. The top boundary was selected to have zero concentration to represent PFT concentrations in the atmosphere which are assumed to be zero. Analysis performed with flow out of the ground surface and into the atmosphere indicated that the zero concentration boundary condition is an excellent approximation due to the higher transport rates in the atmosphere 
(higher diffusion and advection rates).

In the preliminary modeling exercised conducted prior to the experiment, the source was treated as a point source being injected at the centerline at an elevation of $97 \mathrm{~cm}$ above the bottom of the facility. Two injection scenarios were modeled: a 3.7 day pulse injection and continuous injection over the entire simulation period of 37 days. The air injection rate was assumed to be $30 \mathrm{~cm}^{3} / \mathrm{min}$ at a unit tracer concentration. This problem exhibits a linear response to the injection concentration. This property was used to normalize all of the simulation concentrations to the injection concentration.

PFT tracers are non-reactive in soil systems and can be detected at levels of one part in $10^{15}$. Typically, injection concentrations are on the order of one hundred parts per million. Therefore, the detection limit will be approximately $10^{-11}$ of the incoming concentration. One objective of the preliminary modeling work was to define the time at which the PFT's will first be detected at the monitoring wells and the time evolution of concentration at the monitoring wells. For the purposes of defining the experimental protocol, the minimum detection limit was multiplied by a factor of 10,000 for the design objective. This provides a design goal for the normalized concentration in the monitoring wells of $10^{-7}$ over the thirty-six day simulation time Due to the choice of diffusion coefficients in the low end of the expected range for the soil and soil/grout, it is expected that the predicted concentrations will provide a lower bound on the actual concentrations. 


\subsection{Model Results For the Hanford Facility}

\subsubsection{Model Projections Prior to Data Collection}

The computer code BLT [Sullivan and Suen, 1989] was used to solve the above equations for the tracer plume due to injection of the tracer. A wide range of cases was considered to assist in gaining an understanding of the system behavior. The objective of these simulations was to estimate the time evolution of tracer concentration at the monitoring well.

Model simulations of the tracer plume were followed for $3.15 \cdot 10^{6}$ seconds ( 36.5 days) using the base case parameters in Table 1. In the base case it is assumed that the subsurface barrier wall is intact and no substantial breach occurs. In the simulation, tracer was injected for the entire simulation period. The results of this simulation $1.57 \cdot 10^{6} \mathrm{~s}(14.6$ days) after the start of the experiment are presented in Figure 7. The contour plot color key is presented in Figure 8. All projected concentrations are normalized to the injection concentration.

In Figure 9, it is seen that for the base case parameters, the simulated soil/neat cement wall provides an effective barrier to migration of the PFT's. Concentrations at the well 14.6 days since the beginning of tracer injection are more than eight orders of magnitude (which is below the design objective of the experiments and is the lowest value represented on the contour plots) less than the injection concentration. Inspection of the output files indicates that the projected base line concentrations are nine orders of magnitude less than the injection concentration at this 
time. Concentrations at the monitoring well exceeded the design basis value of $10^{-7}$ after thirty days.

Table 1: Transport Parameters for the base case

\begin{tabular}{|l|l|}
\hline Parameter & Value \\
\hline Diffusion Coefficient: Soil & $10^{-2} \mathrm{~cm}^{2} / \mathrm{s}$ \\
\hline Soil/neat cement & $10^{-4} \mathrm{~cm}^{2} / \mathrm{s}$ \\
\hline
\end{tabular}

To determine the effect of the barrier diffusion coefficient on release, the base case was modified by increasing the barrier diffusion coefficient by a factor of 10 to $10^{-3} \mathrm{~cm}^{2} / \mathrm{s}$. This value is expected to be more representative of the soil/neat cement barrier It is in the middle of the range of measured radon diffusion coefficients through residential concretes [Rogers, et al., 1984]. In this case, predicted concentrations at the monitoring well at 14.6 days reached a maximum normalized concentration of $7 \cdot 10^{-6}$ and averaged more than $10^{-6}$. This exceeds the design basis concentration.

\subsubsection{Effect of a Breach on Projected Release from the Barrier}

To determine the effect of a small breach in the barrier a 5-cm hole was simulated as having the same properties as the soil, diffusion coefficient of $10^{-2} \mathrm{~cm}^{2} / \mathrm{s}$. This hypothetical hole in the barrier was located at an elevation of $1.8 \mathrm{~m}$ from the bottom of the modeled domain, $0.8 \mathrm{~m}$ 
higher than the source. The total distance from the source to the edge of the hypothetical hole in the barrier is $1.8 \mathrm{~m}$. The results of this analysis at 14.6 days after the start of the injection, Figure 9, indicate that the breach has a pronounced effect on the tracer plume. Streaming through this 5-cm breach is clearly evident. The peak normalized concentration at the well is $4 \cdot 10^{-6}$. Average normalized concentrations along the lower section of the well are above $10^{-6}$, a three order of magnitude increase over the projected concentration for the intact wall. In fact, the projected concentrations at the monitoring well for the $5-\mathrm{cm}$ hole simulation was of the same order of magnitude as the case with the barrier diffusion coefficient increased an order of magnitude over the base case value.

In all three cases, the tracer plume within the region bounded by the subsurface barrier is almost identical. Average concentrations in this region are approximately $10^{-3}$, four orders of magnitude larger than at the monitoring well location for the case with a barrier breach. This indicates that only a small fraction of the tracer reaches the monitoring wells under the conditions simulated. In fact, after 14 days more than $99 \%$ of the tracer injected is retained in the subsurface barrier region.

The simulated hole size was varied from $1-10 \mathrm{~cm}$ and the results were similar. Even a 1 $\mathrm{cm}$. hole would permit the normalized concentration of PFT tracer that reaches monitoring well to exceed the base case (an intact barrier) value by $2-3$ orders of magnitude in the early stages (i.e. before diffusion through the barrier becomes an important source at the wells). The large increase in predicted release due to a small breach indicates that resolution of breaches on the 
order of a centimeter is theoretically possible.

In the field experiment, a breach would be indicated if the measured concentrations in one of the external monitoring wells differed from the otbers by a several orders of magnitude . Relatively uniform concentrations at each of the monitoring wells indicates that a breach has not occurred.

\subsubsection{Comparison of Experimental Results with Model Predictions}

To test the concept of monitoring barrier performance with PFT's, $\mathrm{PMCH}$ was continually injected for three days into the area contained by the soil/neat cement barrier, Fig. 1, just beneath the empty tank at the center of the region bounded by the cone. Seven monitoring wells were located parallel and approximately 1 meter outside of the barrier. The wells are designated by compass direction, i.e, $\mathrm{N}$ for North, $\mathrm{NE}$ for Northeast, etc. The eighth well at the location designated as West malfunctioned Samples for PMCH were taken from each well beginning three days from the start of injection. Daily sampling occurred between 6 and 17 days except for Saturdays and Sundays.

$\mathrm{PMCH}$ concentrations within the region bounded by the barrier were measured during the three-day injection period The data showed a net drift toward one side of the barrier. The interior monitoring well designated as $\mathrm{N}$, for North, had measured concentrations approximately one order of magnitude greater than the interior well designated $\mathrm{S}$, for south. If diffusion was the 
only transport mechanism, the concentrations at these two wells which are equidistant from the source, would be equal. Therefore, advection is occurring. The cause of this net drift is not known, however, it has been postulated that it is due to the injection flux $\left(0.2-0.25 \mathrm{~cm}^{3} / \mathrm{s}\right)$. The fact that there is a drift indicates that the exterior concentrations in wells near the north side, should exceed those on the south side by an order of magnitude provided the barrier is intact (i.e., no breach)

The time evolution of measured concentration normalized to the injection concentration at the seven monitoring wells is displayed in Figure 10. Each of the monitoring wells shows similar behavior over time. The spread in the measured concentrations is approximately one order of magnitude and this is consistent with the internal well monitoring data, (i.e., highest concentrations are measured on the North side of the facility). The drop in concentration between the inner and outer monitoring wells (i.e., across the barrier) was approximately four orders of magnitude at the end of the injection period of three days. There was no evidence of a substantial breach in any region.

The concentrations displayed in Figure 10 are all normalized to the initial injection concentration of $373 \mathrm{ppm}$. The actual measured PMCH concentrations are in the range of a hundred parts per trillion (normalized concentration of $3 \cdot 10^{-7}$ ) to parts per trillion (normalized concentration of $\left.3 \cdot 10^{-9}\right)$.

To estimate diffusion coefficients in the soil and the barrier, prospective model 
evaluations were performed. The computational model is similar to the one described to examine the influence of a breach in the barrier, Figure 4, with the exception that the dimensions were changed to match the as-built dimensions exactly and the source location was changed to reflect the experimental conditions. The major change in input involved increasing the barrier thickness to 1.15 meters and adjusting the location of the source to directly under the simulated waste tank.

The base case diffusion coefficient estimated values, $D_{\text {soil }}=10^{-2} \mathrm{~cm}^{2} / \mathrm{s}$ and $D_{\text {wall }}=10^{-4}$ $\mathrm{cm}^{2} / \mathrm{s}$, provided concentration estimates that were far lower than the measured value. This was expected because the base case values were chosen with the intent of under predicting the amount that would reach the wells to insure that detection would be possible.

A range of different values of the diffusion coefficients was simulated. The results have been compared to the measured average normalized concentration value of the seven monitoring wells and are displayed in Figure 11. From these evaluations, the soil diffusion coefficient for the PFT has been determined to lie between $1-5 \cdot 10^{-2} \mathrm{~cm}^{2} / \mathrm{s}$ under the test conditions. The diffusion coefficient for the soil/neat cement barrier has been determined to lie between $1-5 \cdot 10^{-3}$ $\mathrm{cm}^{2} / \mathrm{s}$. The best fit was obtained using a soil diffusion coefficient of $2 \cdot 10^{-2} \mathrm{~cm}^{2} / \mathrm{s}$ and a barrier diffusion coefficient of $2 \cdot 10^{-3} \mathrm{~cm}^{2} / \mathrm{s}$. Attempts to improve the fit by regression analysis or other statistical techniques have not been undertaken at this time. At this time, it is felt that due to the net drift exhibited during injection, diffusion was not the only process leading to transport during the injection phase. Therefore, fine tuning the estimate would have little meaning within the 
limits of the data and its interpretation (i.e., diffusion controlled process).

\subsubsection{Modeling Transport Through the Close-Coupled System}

After completion of the PMCH tracer testing for the soil/neat cement barrier, a polymer grout liner was injected on the interior of the barrier to further reduce the potential for transport. Another set of tracer tests were conducted using ocPDCH. In this experiment ocPDCH tracer was injected beneath the buried tank for three days at an injection concentration of $30 \mathrm{ppm}$. The nominal injection rate was $15 \mathrm{~cm}^{3} / \mathrm{min}$.

Test data for the first seventeen days after injection of ocPDCH tracer has been collected and analyzed. The measured data for the first three days is substantially different than that found in the previous test (i.e., when the polymer liner was not present). The normalized internal well concentrations are two orders of magnitude lower (i.e. $10^{-4}$ as compared to $10^{-2}$ ) and external concentrations are approximately two orders of magnitude higher (i.e. $10^{-7}$ as compared to $10^{-9}$ ) when the liner is present. The low concentrations measured in the internal well are not consistent with mass balance calculations which indicate internal normalized concentrations should be around $10^{-2}$. The high concentrations at the external wells are not consistent with diffusion being the dominant transport mechanism.

The cause for this behavior is unknown but may be due to the monitoring techniques which differed between the first and second set of tests. In the first test, interior monitoring wells 
had a solid end and were slotted over a two foot range near the bottom of the pipe. In the second set of tests, the bottom of the pipe used for the monitoring well was open and it was speculated that it may have been partially clogged during emplacement. This would lead to improper mixing in the pipe and lower concentrations. Other possibilities include improper sampling (i.e. neglecting to purge the lines prior to sampling, neglecting to purge the sample collectors, obtaining contaminated samples, or other experimental errors). However, after review of the sampling plan and discussion with the staff that conducted the sampling, it is believed that appropriate sampling procedures were followed.

In addition, sampling along the length of the external monitoring wells was accomplished by inserting a bundle of tubes of differing length inside of the monitoring well. Figure 12 shows the top of the bundle of copper sampling tubes inserted into the well. Figure 13 shows the addition of sand to fill the void space of the monitoring well and thereby isolating the different sampling tubes from each other. Vertical profiling of the external wells indicates relatively uniform concentrations in the north and northwest wells. While the concentrations in the other wells peaks at the bottom of the wells ( $28 \mathrm{ft}$ depth in the plane parallel to the wells). Peak concentrations in the north and northwest wells are a factor of five greater than in the other wells.

A finite-element representation of the subsurface barrier system containing a soil/neat cement outer barrier and a polymer liner has been developed. Several geometries have been considered including: 
a) the polymer liner as designed covering all but the top five feet of the soil/neat cement barrier, contact between the liner and the concrete barrier was assumed

b) the polymer forming a cone at the bottom of the facility with the top of the polymer barrier 1 $1 / 2 \mathrm{ft}$ beneath the tank, contact between the liner and the concrete barrier was assumed., and c) the geometries in $\mathrm{a}$ and $\mathrm{b}$ with a four inch gap between the polymer liner and concrete barrier.

Model results based on the best fit diffusion coefficients for the soil and soil/neat cement region and an assumed polymer liner diffusion coefficient of $2 \cdot 10^{-4} \mathrm{~cm}^{2} / \mathrm{s}$ (a factor of 10 less than in the cement grout) were obtained. The results were unable to satisfactorily duplicate the measured data for the first three days. Model results were much higher (several orders of magnitude) in the region near the injection point, consistent with the mass balance. Model results were consistent with the results of the previous experiment. In the external monitoring wells, model results were generally at least an order of magnitude lower than measured results and the peak concentrations were located at the shortest distance between the source and monitoring wells in the middle region of the wells. Model predictions indicated a two order of magnitude variation in concentration along the length of the well as compared to the relatively uniform concentrations found experimentally. The fact that the measured concentrations were inconsistent with the previous test casts suspicions on the quality of the data.

Data was collected nine and seventeen days after the start of the injection of ocPDCH. This data is more consistent with the previous data collected on the soil/neat cement barrier and modeling projections. At these times, the normalized concentrations at the exterior wells were 
one or two orders of magnitude lower when the polymer liner was present. This would be consistent with the liner providing an additional barrier to release. In addition, there was a net drift from east to west. The tracer ocPDCH was not detected after nine days in the east well, was detected at only one depth in the northeast well, and was detected at low normalized concentrations $\left(<10^{-8}\right)$ in the southeast well. Wells in the northwest, south and southwest had peak normalized concentrations near $2 \cdot 10^{-7}$. Peak normalized concentrations at all wells are displayed in Table 2. From this table it is clear that concentrations at the monitoring wells are increasing by one to two orders of magnitude over this time frame of nine to seventeen days after injection. This is consistent with model projections. Recall that the data after three days indicated external well concentrations on the order of $10^{-7}$. There is no readily explainable physical mechanism that would cause the concentration to raise to this level after three days, fall by one or two orders of magnitude by nine days and then increase by one or two orders of magnitude after 17 days. This casts further suspicion on the quality of the data collected during the first three days.

Due to the questionable quality of the data collected over the first three days, no attempt was made to compare model projections to measured concentrations over the seventeen day time period. The lack of interior well data causes problems in interpreting the long term data and the net drift towards the west indicated that advection was occurring.

Measurements for the PFT PMCH were also made. This tracer was injected in October. Two weeks after the start of the test (beginning of November) the normalized concentrations 
were $10^{-6}$ to $10^{-7}$. During March, PMCH was detected in all wells and the normalized concentrations had decreased by approximately two orders of magnitude to values near $10^{-8}$.

Table 2: Peak Normalized Concentrations of ocPDCH after the three day injection beginning on March 3.

\begin{tabular}{|l|l|l|l|l|}
\hline Well Location & Peak Normalized & Distance & Peak Normalized & Distance \\
& Concentration & along & Concentration & along the \\
& $3 / 12$ & the well & $3 / 20$ & well \\
\hline East & BDL & & BDL & \\
\hline North & $6.1 \mathrm{E}-9$ & 28 & $4 \mathrm{E}-8,3.1 \mathrm{E}-8$ & 8,18 \\
\hline Northeast & & & & $\& 24$ \\
\hline Northwest & BDL & & $2.8 \mathrm{E}-8$ & 20 \\
\hline South & $3.15 \mathrm{E}-8$ & 20 & $2.1 \mathrm{E}-7$ & 26 \\
\hline Southeast & $2.6 \mathrm{E}-9$ & 28 & $1.4 \mathrm{E}-7$ & 24 \\
\hline Southwest & $3.1 \mathrm{E}-9$ & 14 & $8.1 \mathrm{E}-9$ & 20 \\
\hline
\end{tabular}

Data was taken at two foot intervals in each of the exterior sampling wells. These wells were installed parallel to the sloping grout barrier at an angle of 45 degrees relative to the ground surface. Therefore, the depth below grade can be obtained by multiplying the distance along the well by $0.707(\cos (45))$. Therefore, the 20 foot location is at a depth of 14.2 feet. No definite trends in the data with respect to depth were apparent. Concentrations would change by as much 
as a factor of five over a two foot change in location. In addition, low values would be adjacent to higher values. It appeared that higher concentrations were located near the bottom of the wells (22 - 26 foot range) and lower concentrations near the ground surface. However, this was not always the case.

Upon completion of the PFT injection tests for the close-coupled barrier system, the soil surrounding the barrier was excavated. Visual inspections of the close-coupled barrier confirmed that a breach did not occur in either the soil/neat cement or polymer components of the barrier [Dwyer, 1996]. The soil/neat cement barrier had a relatively uniform thickness. Due to the emplacement techniques the polymer liner ranged from $15-30 \mathrm{~cm}$ [Dwyer, 1996].

\subsection{Data Evaluation of the BNL Glass Pit Tracer Tests.}

In this test, the objective was to demonstrate that a large scale breach in the barrier did not occur. This was needed in order to satisfy regulatory issues. The demonstration was achieved through injecting the $30 \mathrm{ppm}$ of PFT ocPDCH at a nominal flow rate of $15 \mathrm{~cm}^{3} / \mathrm{min}$ inside of the cement grout barrier and monitoring on both the inside and outside regions of the barrier, Figure 5. The experiment was conducted during solidification of the source region and therefore, was not a well controlled experiment. The injection lasted approximately one day until the polymer solidified around the injection point. During curing of the polymer, it is likely that thermally driven advective flow patterns may have arisen to bring the PFT to the surface and be released to the atmosphere. 
For all of the above reasons, detailed modeling was not performed. Modeling was limited to simple scoping calculations to estimate the expected concentration drop through the barrier that would occur if no breach occurred. This estimate was used as a basis for determining if a breach had occurred.

Scoping analysis indicated that concentrations should peak near the bottom of the facility due to the location of the injection points and the distance to the sampling points. Concentrations should decrease as the ground surface is approached. If the barrier is intact, normalized concentration seven days after injection should be three orders of magnitude lower outside as compared to inside the barrier. Data was consistent with these predictions. At the four interior wells, the normalized ocPDCH concentrations, Figure 14, were between $1-6 \cdot 10^{-8}$ after the injection and dropped to $0.5-1.5 \cdot 10^{-8}$ one week after the injection was completed. This indicates relatively uniform mixing within the barrier regioñ after one week. At the eight exterior wells, the normalized concentrations ran between $10^{-12}$ and $10^{-9}$. Of approximately 120 exterior samples, about $10 \%$ had normalized concentrations above $10^{-10}$. Most concentrations were below $10^{-11}$. The normalized concentrations from the well designated as E-1, Figure 5, at the 20 feet location is presented in Figure 15. This well was typical of the other wells. The highest external concentrations were located in the wells closest to the SE interior well which exhibited the highest internal concentrations. The concentrations in the exterior wells were approximately the same order of magnitude. The absence of a region of relatively high concentration in the exterior monitoring wells supports the notion that a large scale breach in the barrier does not exist. 
The sensitivity of the measurement technique to the PFT ocPDCH is quite good. Normalized concentrations of $10^{-10}$ are representative of actual concentrations of $3 \cdot 10^{-15}$. In the initial measurement of the gas samples, background concentration samples of VOC's in the parts per trillion range were measured. The presence of VOC's was taken into account when determining PFT concentrations.

\section{CONCLUSIONS}

The proof-of-concept that PFT's could be used as a method for monitoring barrier performance has been demonstrated on a simulated waste pit at Hanford and on an actual waste pit at BNL. Field scale experiments were conducted, the data collected and analyzed. The results support the feasibility of detecting tracers outside of the barrier on the time frame of a few days or weeks for intact barriers.

Modeling of transport of PFT tracers in a subsurface system consisting of soil and a soil/neat cement barrier has been conducted Numerical estimation of the movement of the gas tracer is required because of the complex geometry presented by sloping walls, the presence of wastes, the potential for small breaches, and the dissimilar transport properties in the different materials (soil, cement grout, and polymer). The simulations indicate that for the base case, a two order of magnitude difference in the PFT diffusion coefficient in the soil and barrier, small holes (on the order of $\mathrm{cm}$ ) should be easily detectable. As the difference in diffusion coefficients of the soil and barrier decreases, the ability to detect small holes also decreases. 
Site-specific data on transport parameters were not available. Therefore, the model evaluations were compared to the experimental data and used to estimate the diffusion coefficient for the PFT through the soil and barrier. The best fit to the data indicates that the soil diffusion coefficient is approximately $2 \cdot 10^{-2} \mathrm{~cm}^{2} / \mathrm{s}$ and the barrier diffusion coefficient of $2 \cdot 10^{-3} \mathrm{~cm}^{2} / \mathrm{s}$. These values are in the range of expected values based on diffusion coefficients of other gases through soil systems.

The fact that the barrier emplacement was successful in that no large scale breaches were formed prevented field-scale demonstration of the accuracy of PFT's in defining a breach. Model evaluations indicate the feasibility of locating breaches down to a few $\mathrm{cm}$ in size. However, experimental verification of this concept is needed. It is recommended that tests be performed on subsurface barriers with pre-formed breaches of known location, size, and geometry. In addition, work should be done for partial breach failure (e.g. a region with half-the thickness of the barrier) to simulate improper grouting. These types of tests are needed to permit demonstration of the resolution that can be obtained by using PFT's and build confidence in the ability to understand, monitor, and predict the behavior of subsurface barriers.

More experience is needed in the application and development of simulation models used to estimate the size and location of potential small scale breaches or barrier imperfections for realistic geometries and on the field scale. Areas with unresolved issues include: transport parameter estimation, breach location and size determination, the role of advection on transport, estimation of spacing requirements between PFT monitoring locations that are needed to define 
a breach, inverse modeling to define a breach, the role of small scale heterogeneities and experimental uncertainties in influencing estimates of breach location and the role of simultaneous use of different PFT tracers to evaluate barrier performance. 


\section{References}

D’Ottavio, T.W. and R.N. Dietz, (1987). “Radon Source Rate Measurements using

Perfluorocarbon Tracers," Indoor Air '87, 4th International Conference on Indoor Air Quality and Climate, Berlin, Germany.

Dwyer, B. P. J. Heiser, and W. Stewart (1996). "Demonstration of Close-Coupled Barriers for Subsurface Containment of Buried Waste," Spectrum '96, Proceedings of the International Topical Meeting on Nuclear and Hazardous Waste Management, pp. 359 - 366.

Heiser, J., (1994). "Subsurface Barrier Verification Technologies," Brookhaven National Laboratory, Upton, NY, BNL-61127.

Horn, E.G., R.N. Dietz, R.M. Aldous, G. A. Leadon, L.J. Honan, and K.KK. Seiffert, (1991). EPRI 1991 PCB Seminar, Baltimore, MD.

Nielson, K. K., and V.C. Rogers, (1982). “A Mathematical Model for Radon Diffusion in Earthen Materials," NUREG/CR-2765, U.S. Nuclear Regulatory Commission, Washington, D.C.

Rogers, V.C., K.K. Nielson, R.B. Holt, and R. Snoddy, (1984). "Radon Diffusion Coefficients for Residential Concretes," Health Physics, Vol. 67, No. 3, pp. 261 - 265.

Siskind, B., and J. Heiser, (1993). "Regulatory Issues and Assumptions Associated with Barriers 
in the Vadose Zone Surrounding Buried Waste," BNL-48749(1), Environmental and Waste Technology Center, Brookhaven National Laboratory.

Sullivan, T. M., and C.J. Suen, (1989). "Low-Level Waste Shallow Land Disposal Source Term Model: Data Input Guides, “NUREG/CR-5387.

Sullivan, T.M., A. Gard, and J. Heiser, (1996). "Modeling of Subsurface Barrier Performance," Waste Management '96, Tucson, AZ. 
APPENDIX A:

PMCH Tracer Data 


\begin{tabular}{|c|c|c|c|c|c|c|}
\hline Site & Date & Time & $\begin{array}{l}\mathrm{PMCH} \\
\mathrm{pL} / \mathrm{L}\end{array}$ & $\begin{array}{l}\text { Normalized } \\
\text { Concentration }\end{array}$ & $\begin{array}{c}\text { Time } \\
\text { after } \\
\text { injection }\end{array}$ & (days) \\
\hline$E$ & $10 / 20 / 95$ & 745 AM & $2.78 \mathrm{E}-01$ & $7.45 E-10$ & 66 & 2.75 \\
\hline$E$ & $10 / 23 / 95$ & 235PM & 7.12E-01 & 1.91E-09 & 145 & 6.04 \\
\hline$E$ & $10 / 24 / 95$ & 230PM & $1.38 E+00$ & 3.71E-09 & 169 & 7.04 \\
\hline$E$ & $10 / 25 / 95$ & 245PM & $9.54 \mathrm{E}+00$ & 2.56E-08 & 193 & 8.04 \\
\hline$E$ & $10 / 26 / 95$ & 245PM & $1.13 E+01$ & 3.02E-08 & 217 & 9.04 \\
\hline$E$ & $10 / 27 / 95$ & 100PM & 2.37E+01 & $6.34 E-08$ & 240 & 10.00 \\
\hline$E$ & $10 / 30 / 95$ & 250PM & $6.08 E+01$ & 1.63E-07 & 313 & 13.04 \\
\hline$E$ & $10 / 31 / 95$ & 255PM & $4.56 \mathrm{E}+01$ & 1.22E-07 & 337 & 14.04 \\
\hline$E$ & $11 / 1 / 95$ & $100 \mathrm{PM}$ & $5.85 \mathrm{E}+01$ & 1.57E-07 & 360 & 15.00 \\
\hline$E$ & $11 / 2 / 95$ & 230PM & $8.24 E+01$ & 2.21E-07 & 385 & 16.04 \\
\hline$E$ & $11 / 3 / 95$ & $200 \mathrm{PM}$ & $8.25 \mathrm{E}+01$ & 2.21E-07 & 409 & 17.04 \\
\hline$N$ & $10 / 20 / 95$ & $745 \mathrm{AM}$ & $5.98 \mathrm{E}-01$ & $1.60 E-09$ & 66 & 2.75 \\
\hline $\mathrm{N}$ & $10 / 23 / 95$ & 235PM & $5.87 \mathrm{E}+01$ & 1.57E-07 & 145 & 6.04 \\
\hline$N$ & $10 / 24 / 95$ & 230PM & $1.28 E+02$ & 3.42E-07 & 169 & 7.04 \\
\hline$N$ & $10 / 25 / 95$ & 245PM & $4.08 E+02$ & 1.09E-06 & 193 & 8.04 \\
\hline$N$ & $10 / 26 / 95$ & 245PM & $5.88 E+02$ & 1.58E-06 & 217 & 9.04 \\
\hline$N$ & $10 / 27 / 95$ & $100 \mathrm{PM}$ & $6.54 \mathrm{E}+02$ & 1.75E-06 & 240 & 10.00 \\
\hline$N$ & $10 / 30 / 95$ & 250PM & $9.67 E+02$ & 2.59E-06 & 313 & 13.04 \\
\hline$N$ & $10 / 31 / 95$ & 255PM & $9.96 \mathrm{E}+02$ & 2.67E-06 & 337 & 14.04 \\
\hline $\mathrm{N}$ & $11 / 1 / 95$ & $100 \mathrm{PM}$ & $1.15 E+03$ & $3.08 E-06$ & 360 & 15.00 \\
\hline $\mathrm{N}$ & $11 / 2 / 95$ & 230PM & $1.15 \mathrm{E}+03$ & $3.08 E-06$ & 385 & 16.04 \\
\hline$N$ & $11 / 3 / 95$ & 200PM & $1.19 \mathrm{E}+03$ & $3.18 E-06$ & 409 & 17.04 \\
\hline NE & $10 / 20 / 95$ & $745 \mathrm{AM}$ & 3.84E-01 & 1.03E-09 & 66 & 2.75 \\
\hline NE & $10 / 23 / 95$ & 235PM & $4.86 E+00$ & 1.30E-08 & 145 & 6.04 \\
\hline NE & $10 / 24 / 95$ & 230PM & $1.26 E+01$ & 3.39E-08 & 169 & 7.04 \\
\hline NE & $10 / 25 / 95$ & 245PM & $3.99 E+01$ & 1.07E-07 & 193 & 8.04 \\
\hline NE & $10 / 26 / 95$ & 245PM & $5.81 E+01$ & 1.56E-07 & 217 & 9.04 \\
\hline NE & $10 / 27 / 95$ & $100 \mathrm{PM}$ & 7.47E+01 & 2.00E-07 & 240 & 10.00 \\
\hline NE & $10 / 30 / 95$ & $250 \mathrm{PM}$ & $1.34 \mathrm{E}+02$ & 3.59E-07 & 313 & 13.04 \\
\hline NE & $10 / 31 / 95$ & 255PM & 1.31E+02 & 3.51E-07 & 337 & 14.04 \\
\hline NE & $11 / 1 / 95$ & 100PM & $1.49 E+02$ & 4.00E-07 & 360 & 15.00 \\
\hline $\mathrm{NE}$ & $11 / 2 / 95$ & 230PM & $1.30 E+02$ & $3.48 E-07$ & 385 & 16.04 \\
\hline $\mathrm{NE}$ & $11 / 3 / 95$ & 200PM & $1.63 E+02$ & 4.37E-07 & 409 & 17.04 \\
\hline NW & $10 / 20 / 95$ & 745 AM & 4.14E-01 & 1.11E-09 & 66 & 2.75 \\
\hline NW & $10 / 23 / 95$ & 235PM & $4.10 E+01$ & 1.10E-07 & 145 & 6.04 \\
\hline NW & $10 / 24 / 95$ & 230PM & $6.88 \mathrm{E}+01$ & 1.84E-07 & 169 & 7.04 \\
\hline NW & $10 / 25 / 95$ & 245PM & $2.20 \mathrm{E}+02$ & 5.90E-07 & 193 & 8.04 \\
\hline NW & $10 / 26 / 95$ & 245PM & $2.88 E+02$ & 7.73E-07 & 217 & 9.04 \\
\hline NW & $10 / 27 / 95$ & $100 \mathrm{PM}$ & $3.40 E+02$ & 9.12E-07 & 240 & 10.00 \\
\hline NW & $10 / 30 / 95$ & $250 \mathrm{PM}$ & $5.55 \mathrm{E}+02$ & 1.49E-06 & 313 & 13.04 \\
\hline NW & $10 / 31 / 95$ & 255PM & $6.60 E+02$ & 1.77E-06 & 337 & 14.04 \\
\hline NW & $11 / 1 / 95$ & $100 \mathrm{PM}$ & $6.68 \mathrm{E}+02$ & 1.79E-06 & 360 & 15.00 \\
\hline NW & $11 / 2 / 95$ & 230PM & $1.01 E+03$ & 2.71E-06 & 385 & 16.04 \\
\hline NW & $11 / 3 / 95$ & 200PM & $7.12 E+02$ & 1.91E-06 & 409 & 17.04 \\
\hline$S$ & $10 / 20 / 95$ & 745 AM & 3.64E-01 & $9.76 E-10$ & 66 & 2.75 \\
\hline S & $10 / 23 / 95$ & 235PM & $5.75 \mathrm{E}+00$ & 1.54E-08 & 145 & 6.04 \\
\hline$S$ & $10 / 24 / 95$ & 230PM & $1.38 E+01$ & 3.71E-08 & 169 & 7.04 \\
\hline $\mathrm{S}$ & $10 / 25 / 95$ & 245PM & $3.97 E+01$ & 1.06E-07 & 193 & 8.04 \\
\hline$S$ & $10 / 26 / 95$ & 245PM & $6.34 E+01$ & 1.70E-07 & 217 & 9.04 \\
\hline
\end{tabular}




\begin{tabular}{|c|c|c|c|c|c|c|}
\hline Site & Date & Time & $\begin{array}{l}\mathrm{PMCH} \\
\mathrm{pL} / \mathrm{L}\end{array}$ & $\begin{array}{l}\text { Normalized } \\
\text { Concentration }\end{array}$ & $\begin{array}{c}\text { Time } \\
\text { after } \\
\text { injection }\end{array}$ & (days) \\
\hline $\mathrm{s}$ & $10 / 27 / 95$ & 100PM & $7.26 E+01$ & 1.95E-07 & 240 & 10.00 \\
\hline$S$ & $10 / 30 / 95$ & 250PM & $1.15 E+02$ & $3.08 \mathrm{E}-07$ & 313 & 13.04 \\
\hline$S$ & $10 / 31 / 95$ & 255PM & $1.54 E+02$ & 4.14E-07 & 337 & 14.04 \\
\hline$S$ & $11 / 1 / 95$ & 100PM & $1.68 E+02$ & 4.51E-07 & 360 & 15.00 \\
\hline$S$ & $11 / 2 / 95$ & 230PM & $1.40 E+02$ & 3.76E-07 & 385 & 16.04 \\
\hline$S$ & $11 / 3 / 95$ & 200PM & 1.47E+02 & 3.94E-07 & 409 & 17.04 \\
\hline SE & $10 / 23 / 95$ & 235PM & $5.41 E+00$ & $1.45 \mathrm{E}-08$ & 145 & 6.04 \\
\hline SE & $10 / 24 / 95$ & $230 P M$ & $1.16 \mathrm{E}+01$ & 3.10E-08 & 169 & 7.04 \\
\hline SE & $10 / 25 / 95$ & 245PM & $3.85 E+01$ & 1.03E-07 & 193 & 8.04 \\
\hline SE & $10 / 26 / 95$ & 245PM & $5.48 \mathrm{E}+01$ & 1.47E-07 & 217 & 9.04 \\
\hline SE & $10 / 27 / 95$ & $100 \mathrm{PM}$ & $7.24 \mathrm{E}+01$ & $1.94 \mathrm{E}-07$ & 240 & 10.00 \\
\hline SE & $10 / 30 / 95$ & 250PM & $1.08 E+02$ & 2.90E-07 & 313 & 13.04 \\
\hline SE & $10 / 31 / 95$ & 255PM & $1.26 \mathrm{E}+02$ & 3.38E-07 & 337 & 14.04 \\
\hline SE & $11 / 1 / 95$ & $100 \mathrm{PM}$ & $1.36 E+02$ & 3.63E-07 & 360 & 15.00 \\
\hline SE & $11 / 3 / 95$ & $200 P M$ & $1.59 E+02$ & $4.25 \mathrm{E}-07$ & 409 & 17.04 \\
\hline SW & $10 / 20 / 95$ & $745 \mathrm{AM}$ & 2.60E-01 & 6.97E-10 & 66 & 2.75 \\
\hline sw & $10 / 23 / 95$ & 235PM & $1.93 E+01$ & $5.18 \mathrm{E}-08$ & 145 & 6.04 \\
\hline sw & $10 / 24 / 95$ & 230PM & $4.27 E+01$ & 1.14E-07 & 169 & 7.04 \\
\hline SW & $10 / 25 / 95$ & 245PM & $1.16 \mathrm{E}+02$ & $3.12 E-07$ & 193 & 8.04 \\
\hline sw & $10 / 26 / 95$ & 245PM & $1.64 \mathrm{E}+02$ & 4.40E-07 & 217 & 9.04 \\
\hline SW & $10 / 27 / 95$ & $100 \mathrm{PM}$ & $1.95 E+02$ & 5.22E-07 & 240 & 10.00 \\
\hline sw & $10 / 30 / 95$ & $250 \mathrm{PM}$ & $4.62 E+02$ & $1.24 \mathrm{E}-06$ & 313 & 13.04 \\
\hline SW & $10 / 31 / 95$ & 255PM & $3.61 E+02$ & 9.69E-07 & 337 & 14.04 \\
\hline SW & 11/1/95 & 100PM & $3.74 E+02$ & $1.00 \mathrm{E}-06$ & 360 & 15.00 \\
\hline SW & $11 / 2 / 95$ & $230 \mathrm{PM}$ & $1.42 E+02$ & 3.82E-07 & 385 & 16.04 \\
\hline SW & $11 / 3 / 95$ & 200PM & $4.36 E+02$ & $1.17 \mathrm{E}-06$ & 409 & $\begin{array}{c}17.04 \\
0.00\end{array}$ \\
\hline Inside N & $10 / 17 / 95$ & $430 \mathrm{pm}$ & $7.00 E+02$ & $1.88 \mathrm{E}-06$ & 3 & 0.13 \\
\hline Inside N & $10 / 18 / 95$ & 836am & $7.30 E+02$ & 1.96E-06 & 19 & 0.79 \\
\hline Inside $N$ & $10 / 18 / 95$ & 200pm & $1.10 E+06$ & 2.95E-03 & 24.5 & 1.02 \\
\hline Inside N & $10 / 19 / 95$ & 1045am & $4.10 E+06$ & 1.10E-02 & 45.25 & 1.89 \\
\hline Inside N & $10 / 19 / 95$ & $121 p m$ & $4.23 E+06$ & 1.13E-02 & 48 & 2.00 \\
\hline Inside N & $10 / 20 / 95$ & 932am & $1.09 E+07$ & 2.92E-02 & 68 & $\begin{array}{l}2.83 \\
0.00\end{array}$ \\
\hline Inside S & $10 / 18 / 95$ & $430 \mathrm{pm}$ & $3.10 E+04$ & 8.31E-05 & 3 & 0.13 \\
\hline Inside S & $10 / 19 / 95$ & $1040 \mathrm{am}$ & $2.10 E+05$ & 5.63E-04 & 45.25 & 1.89 \\
\hline Inside S & $10 / 19 / 95$ & $138 p m$ & $2.63 E+05$ & 7.05E-04 & 48 & 2.00 \\
\hline Inside S & $10 / 20 / 95$ & $940 a m$ & $9.37 E+05$ & $2.51 \mathrm{E}-03$ & 68 & $\begin{array}{l}2.83 \\
0.00\end{array}$ \\
\hline SE & $11 / 2 / 95$ & 230PM & 1.82E-01 & $4.88 \mathrm{E}-10$ & 385 & 16.04 \\
\hline SE & $10 / 20 / 95$ & 745 AM & $0.00 E+00$ & $0.00 E+00$ & 66 & 2.75 \\
\hline
\end{tabular}




\section{Schematic of the Hanford subsurface barrier system}

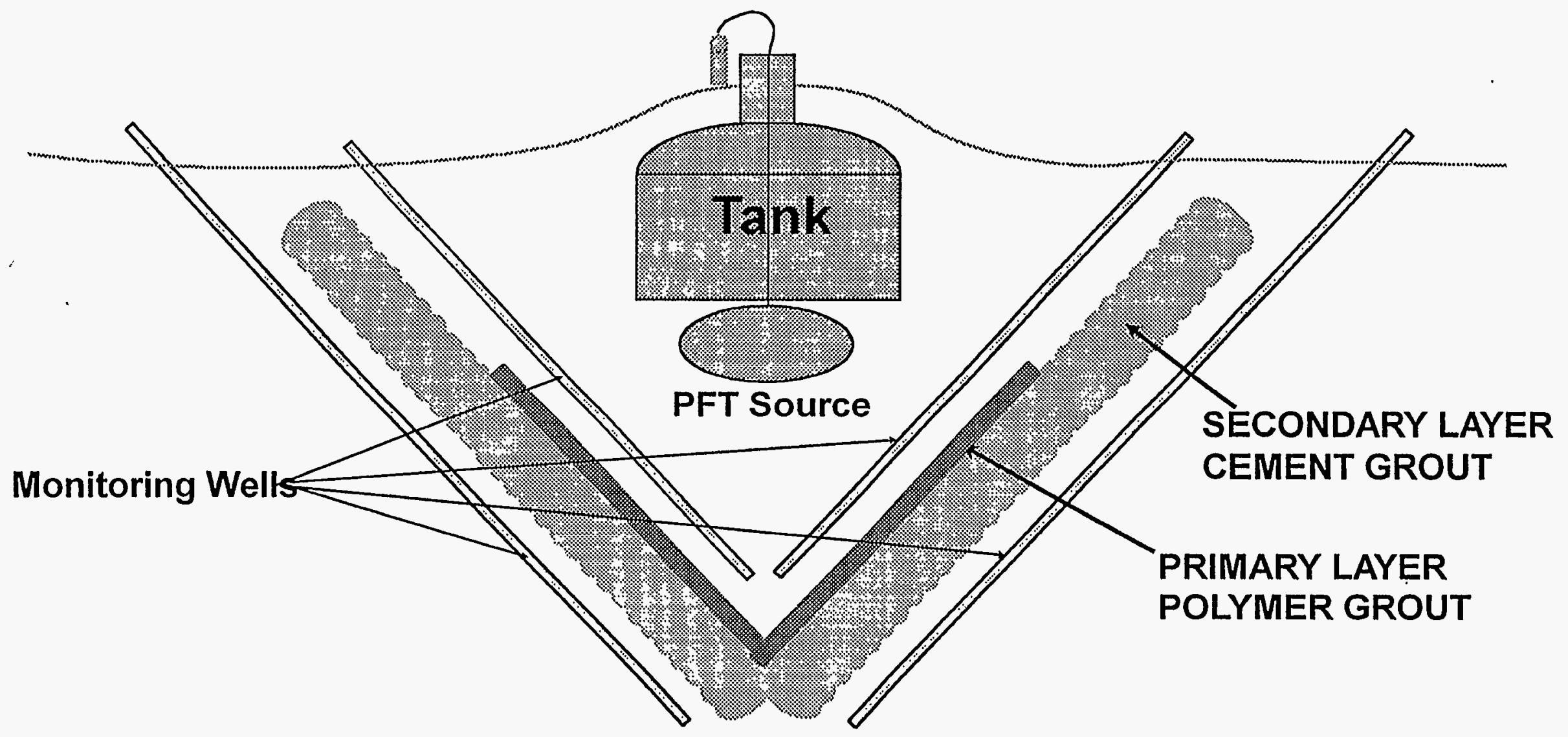

Figure 1. Schematic drawing of the side view of the Hanford subsurface barrier system. 


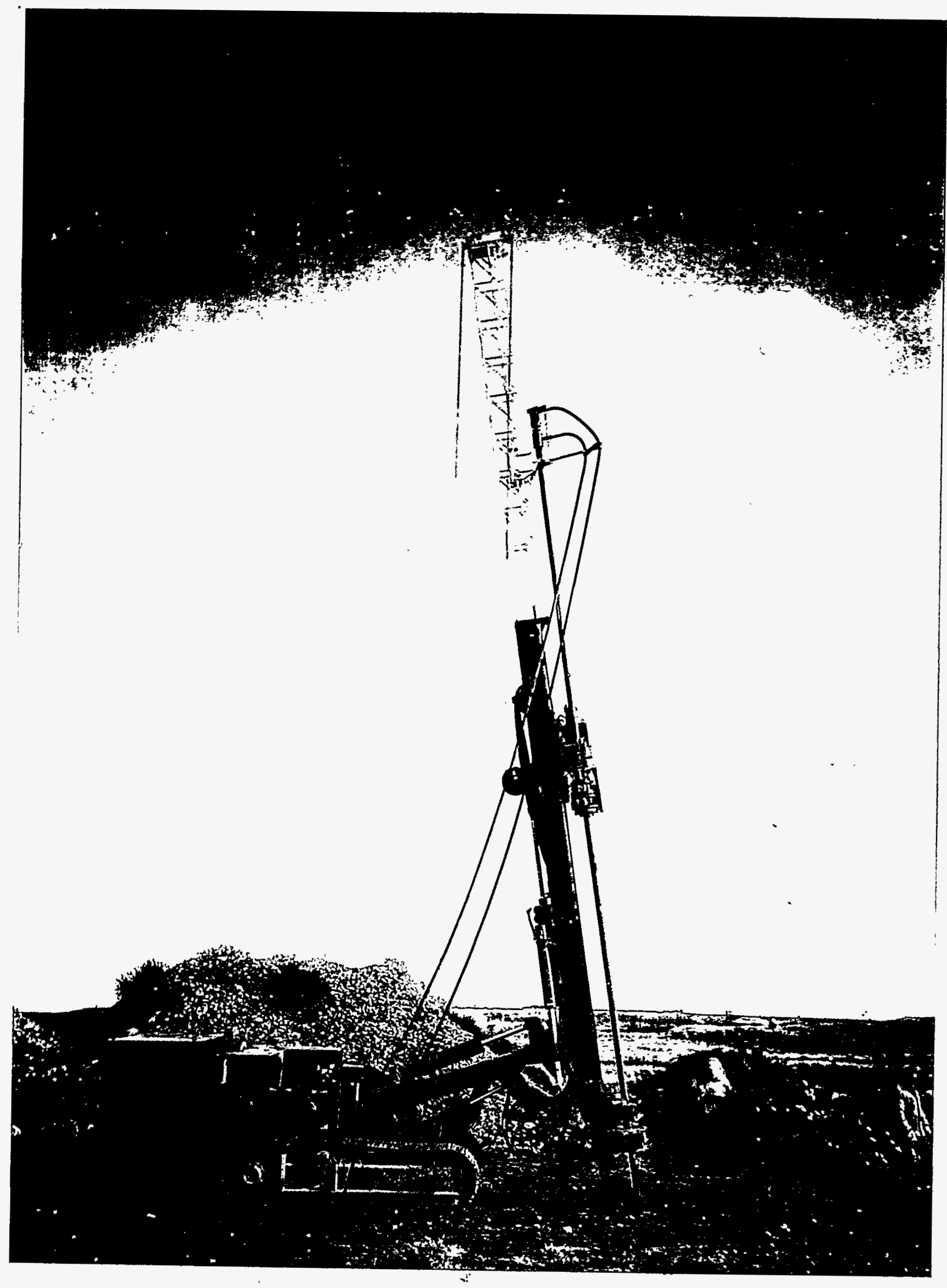

Figure 2. Grout Injection system used at Hanford. 


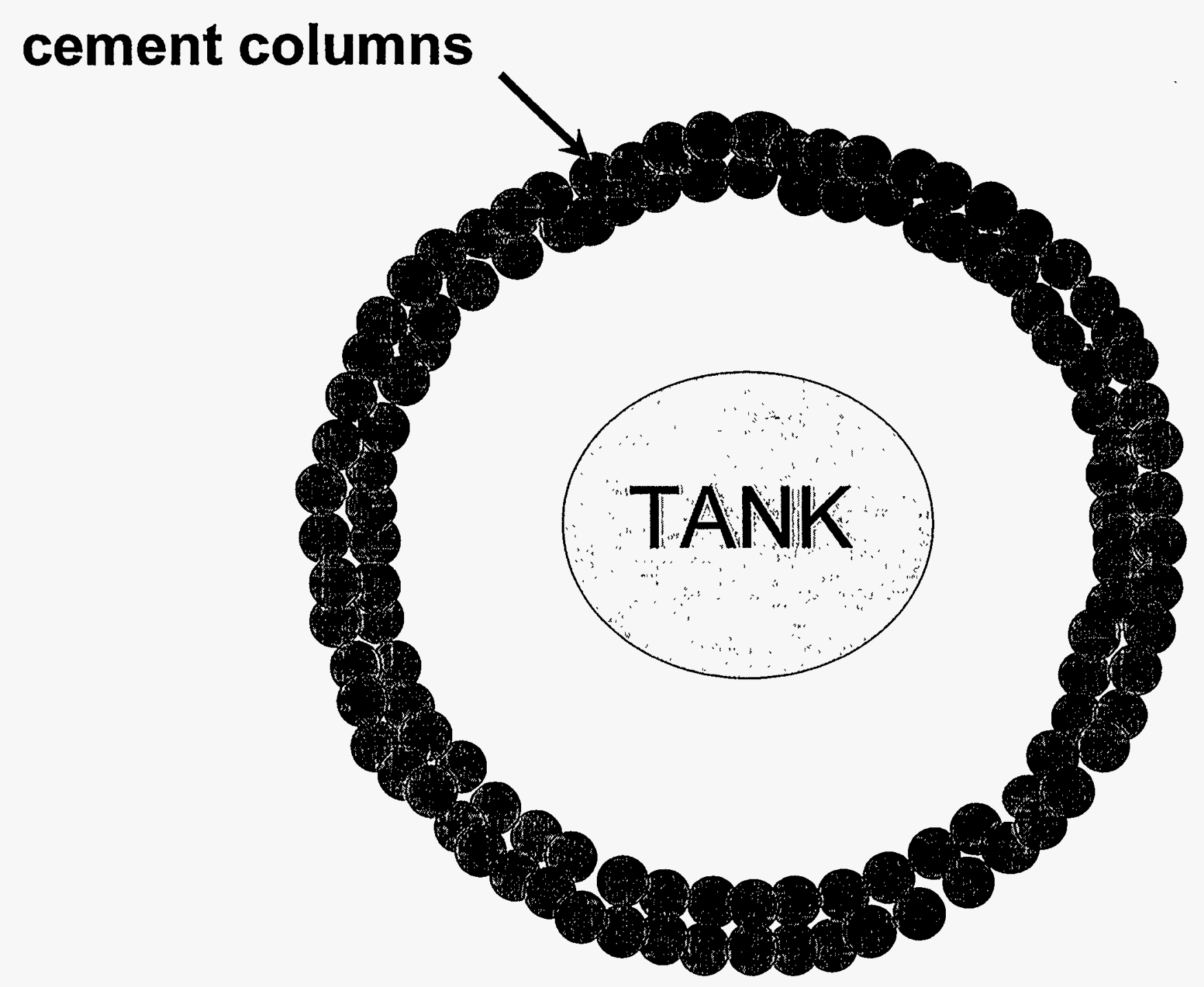

Figure 3: Schematic top view of the Hanford cementitious grout subsurface barrier system 


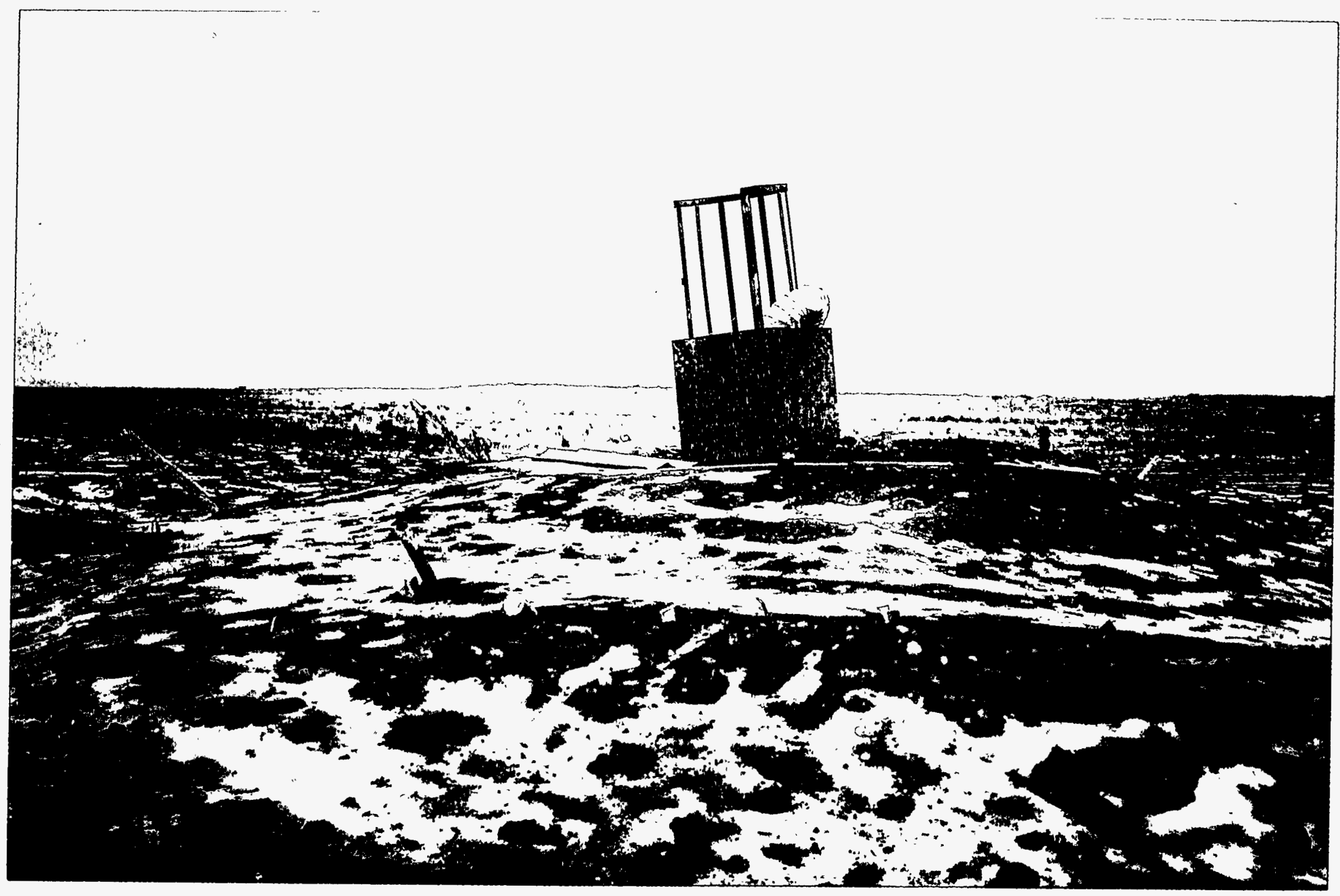

Figure 4. Ground view of the Hanford Subsurface Barrier System. 


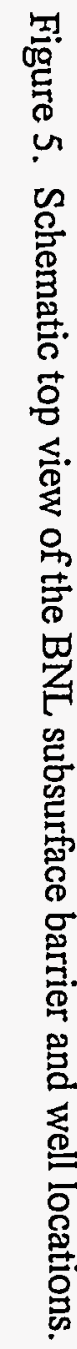

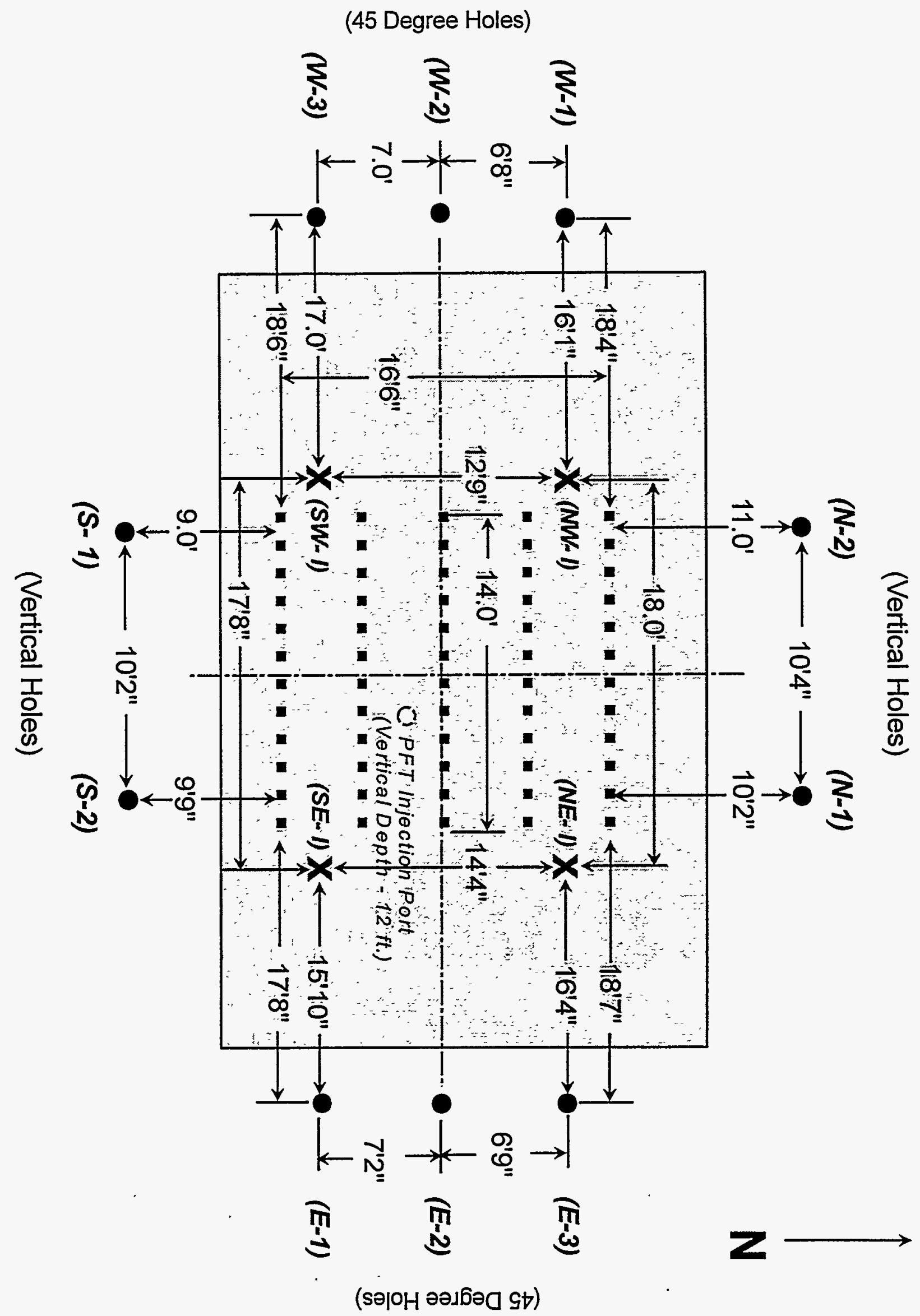


Figure 6. Finite Element Grid Used to Simulate Transport Through the Subsurface Barrier System

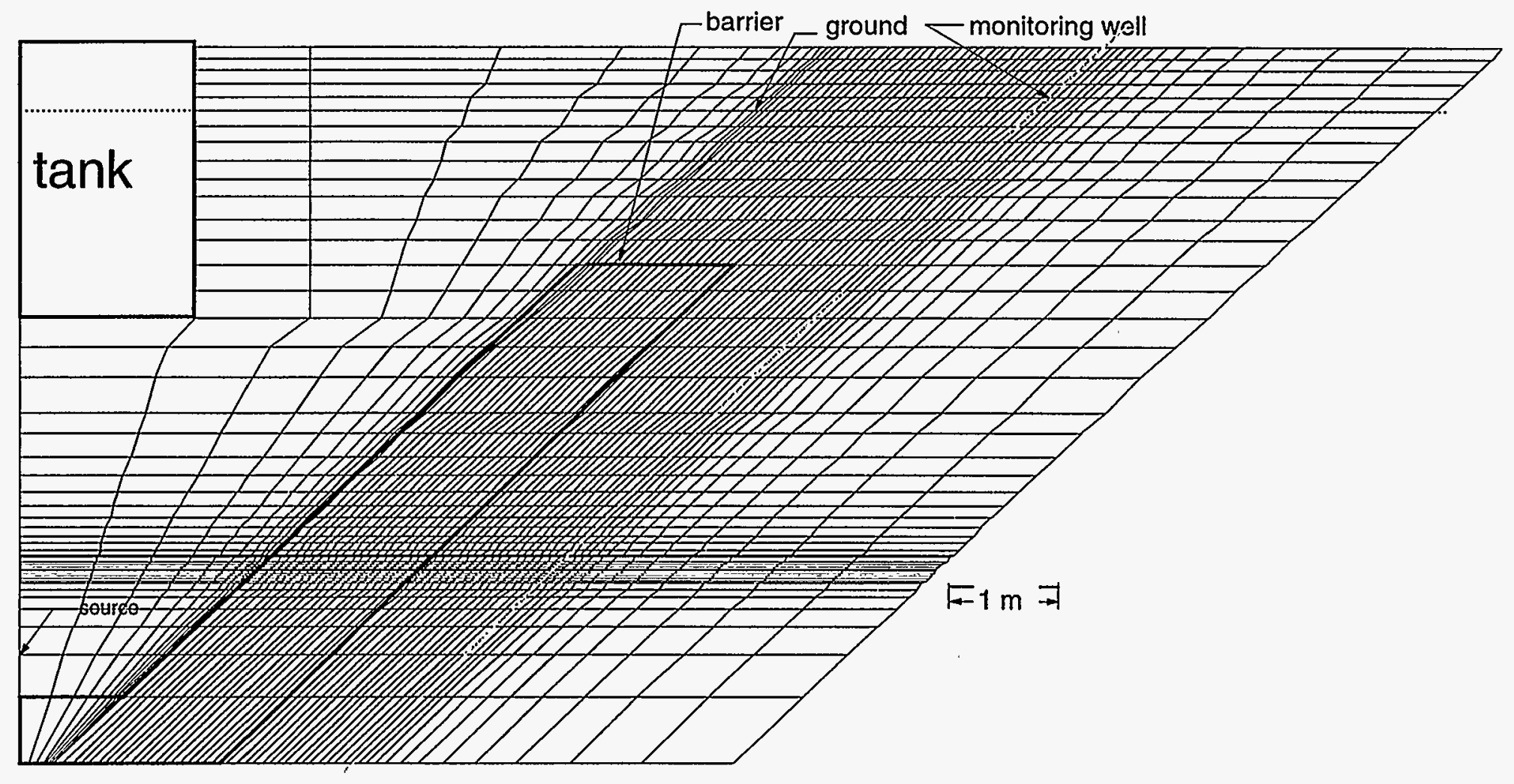




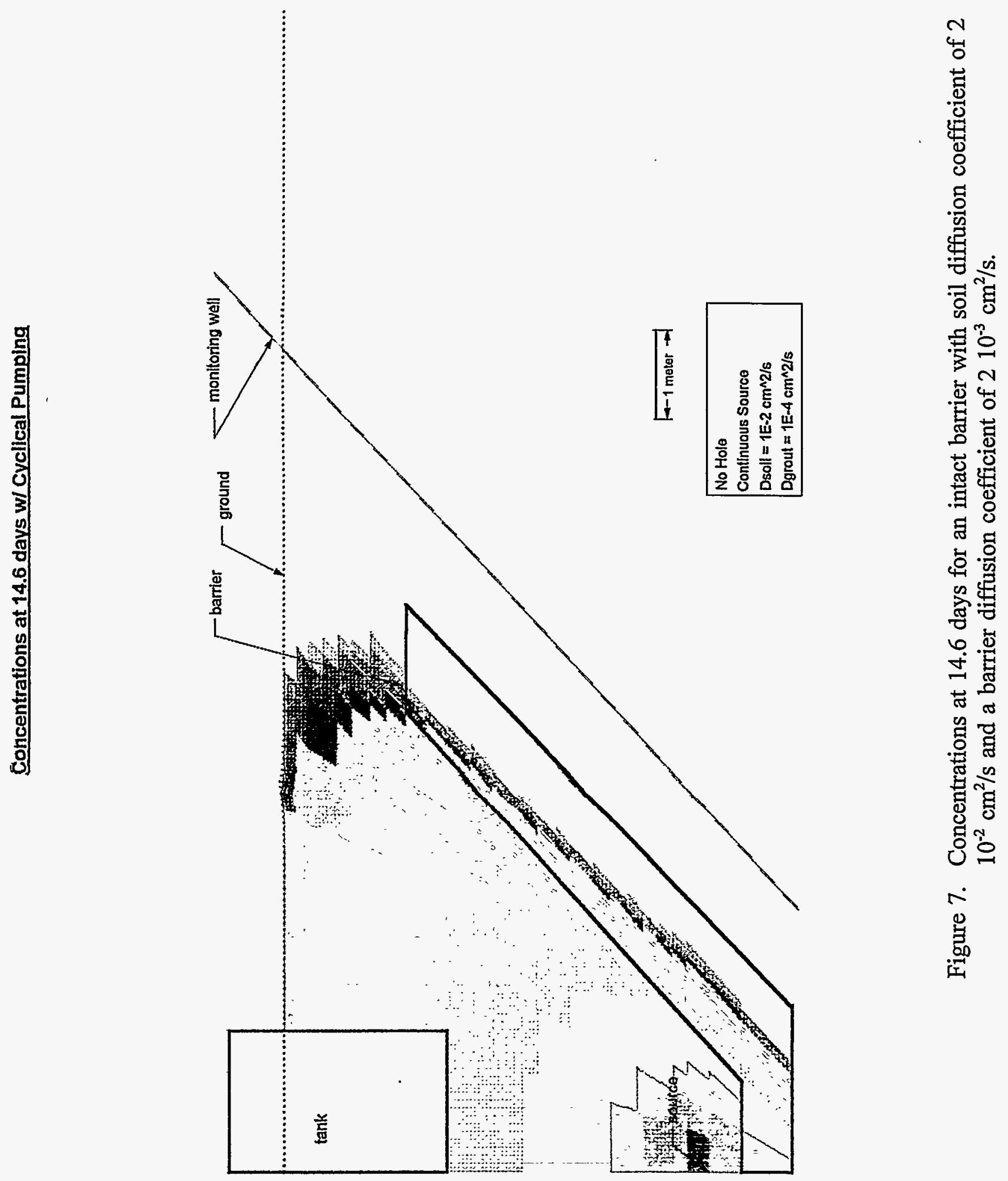




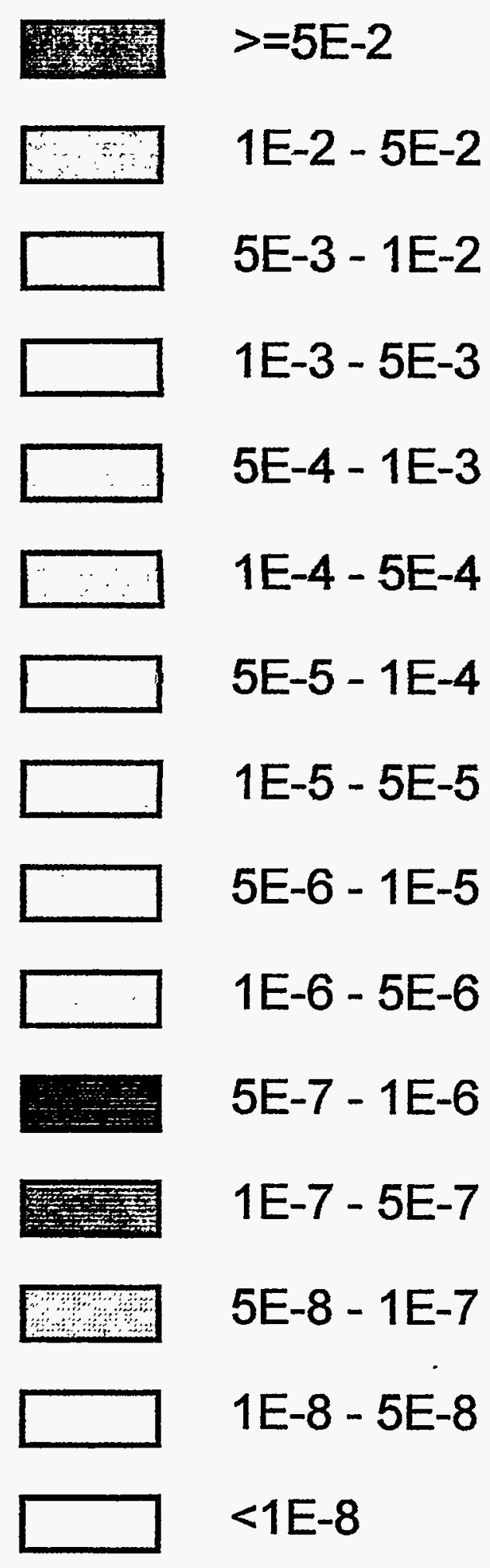



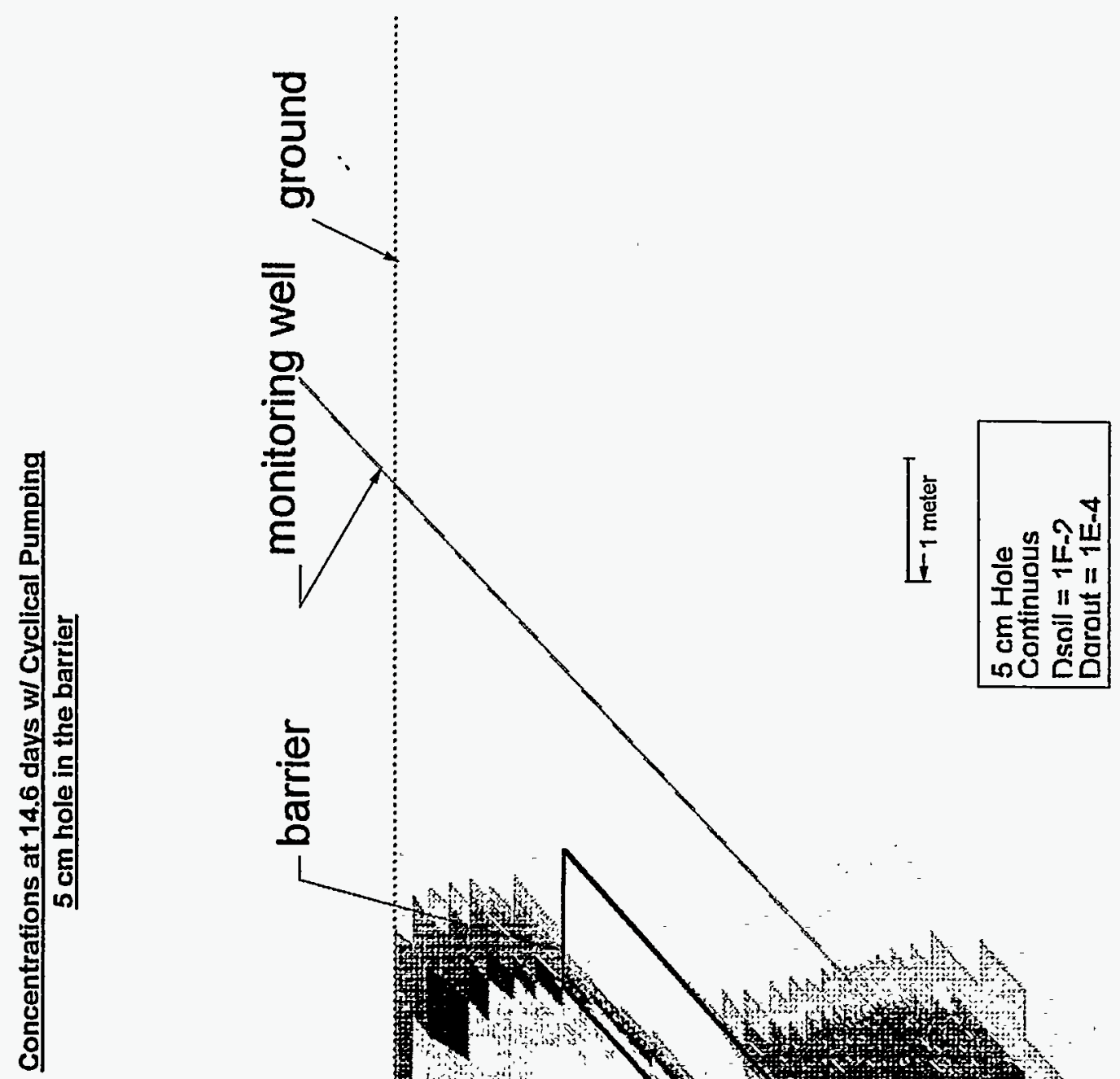

总
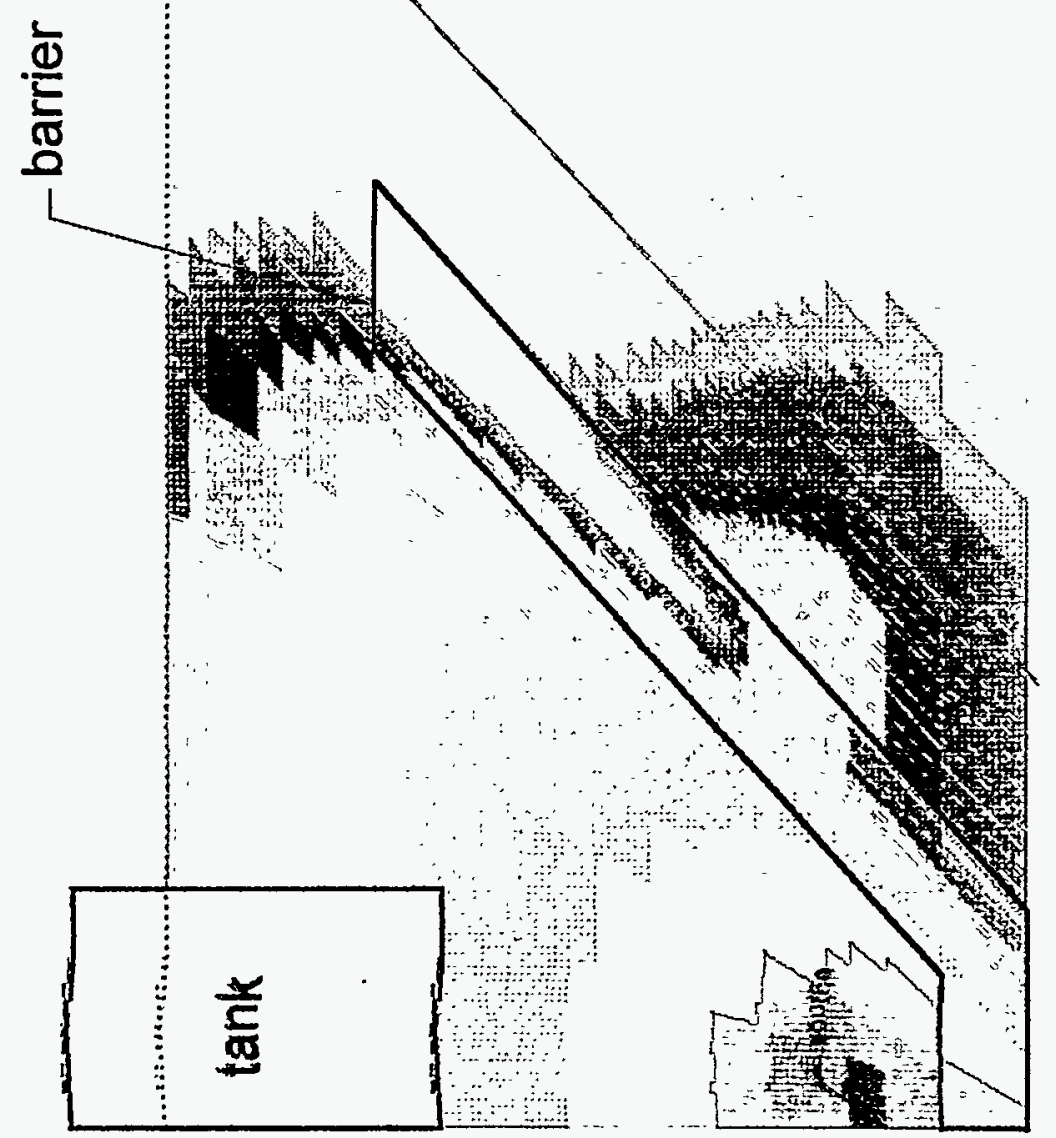

몀 뗭

뎡 范

苋 


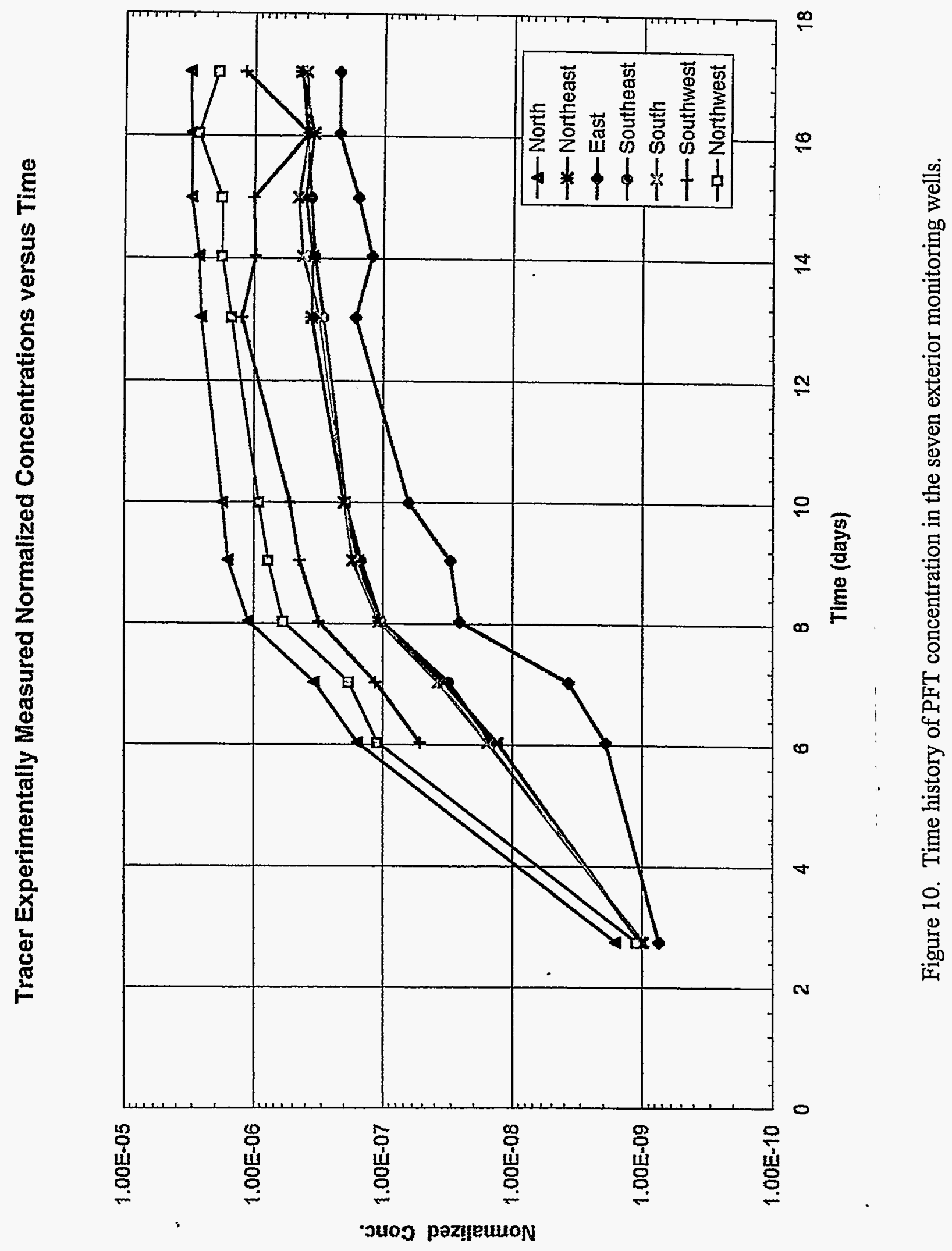




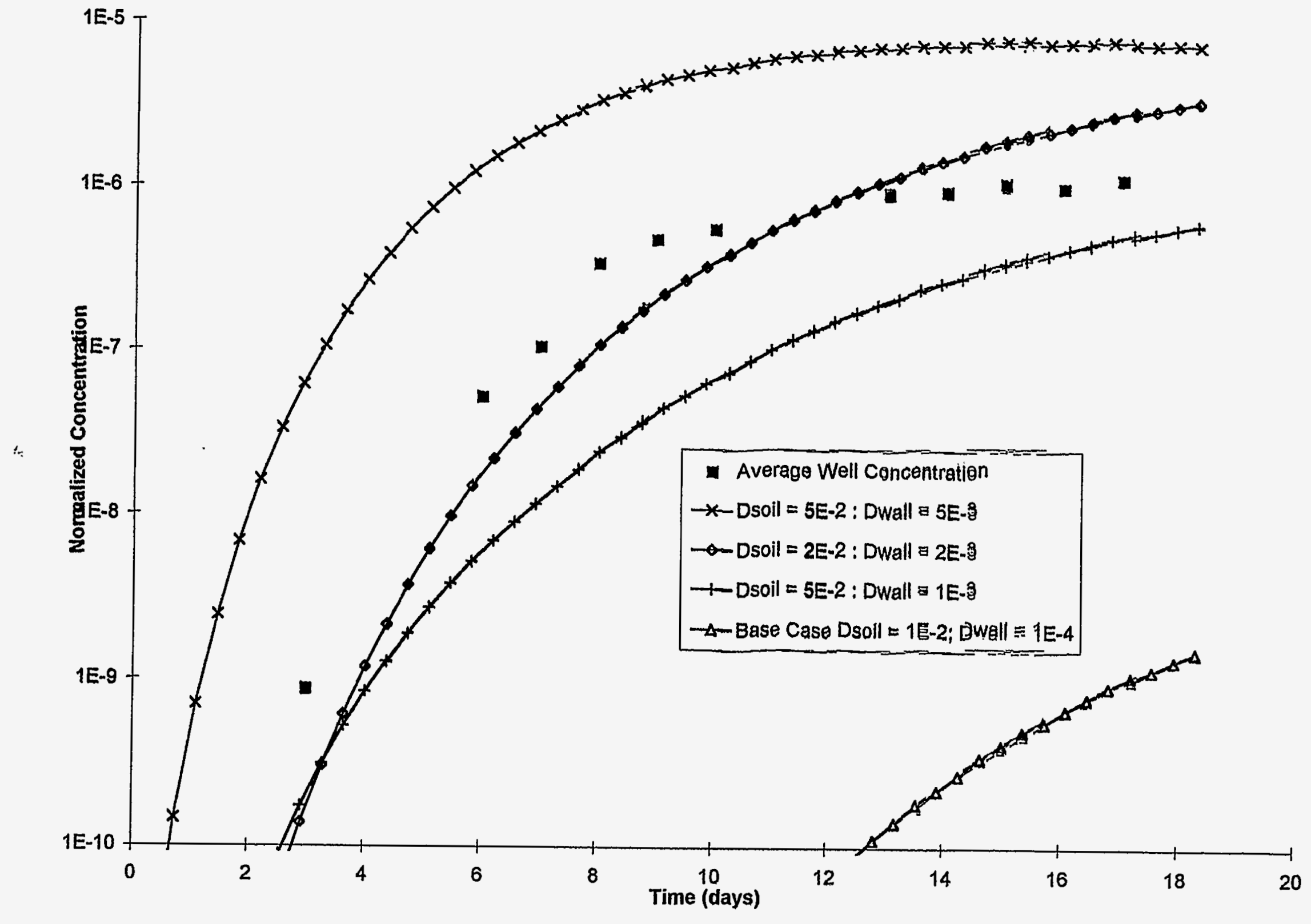

Figure 11. Comparison of the time history of the average monitoring well concentrations with model results. 


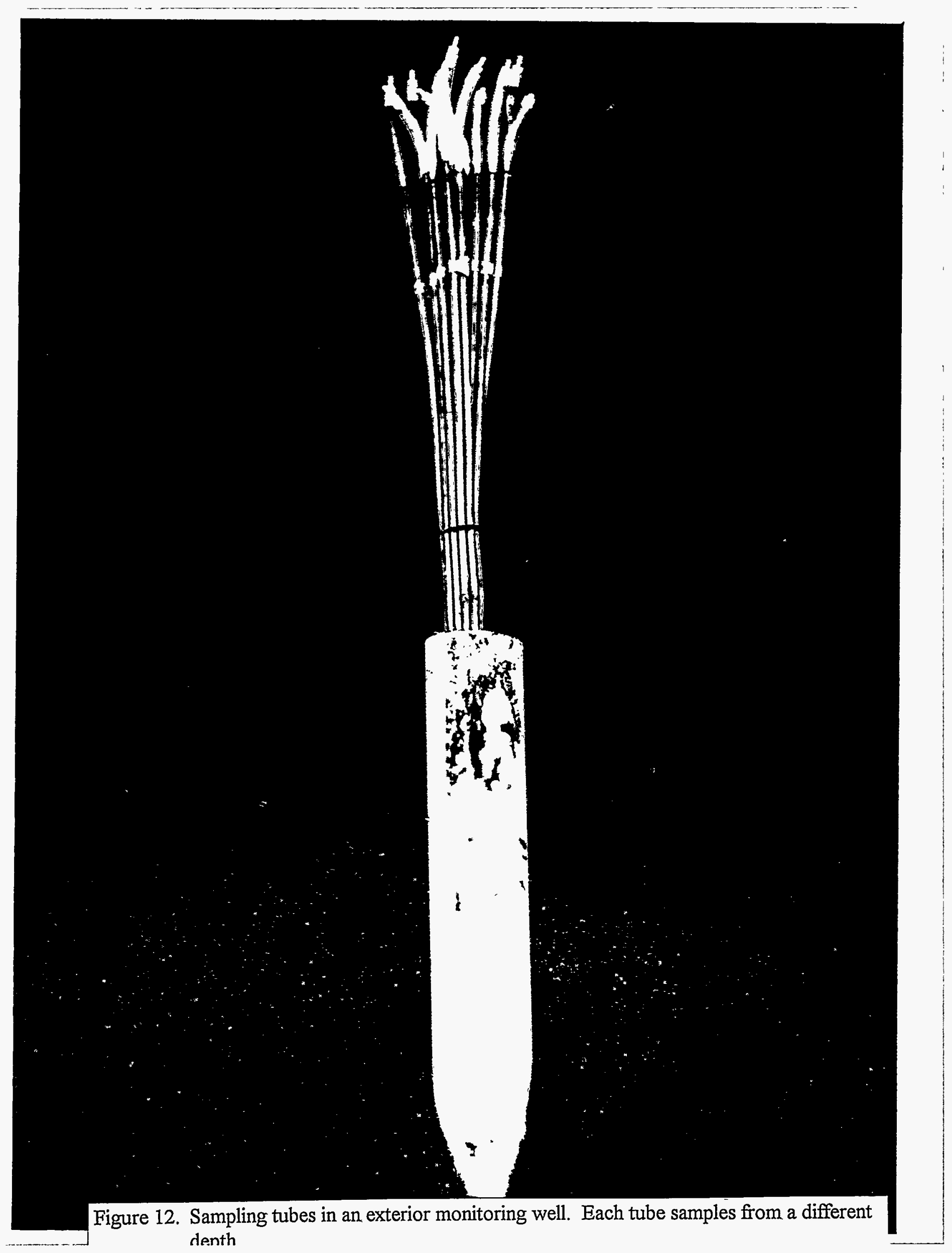




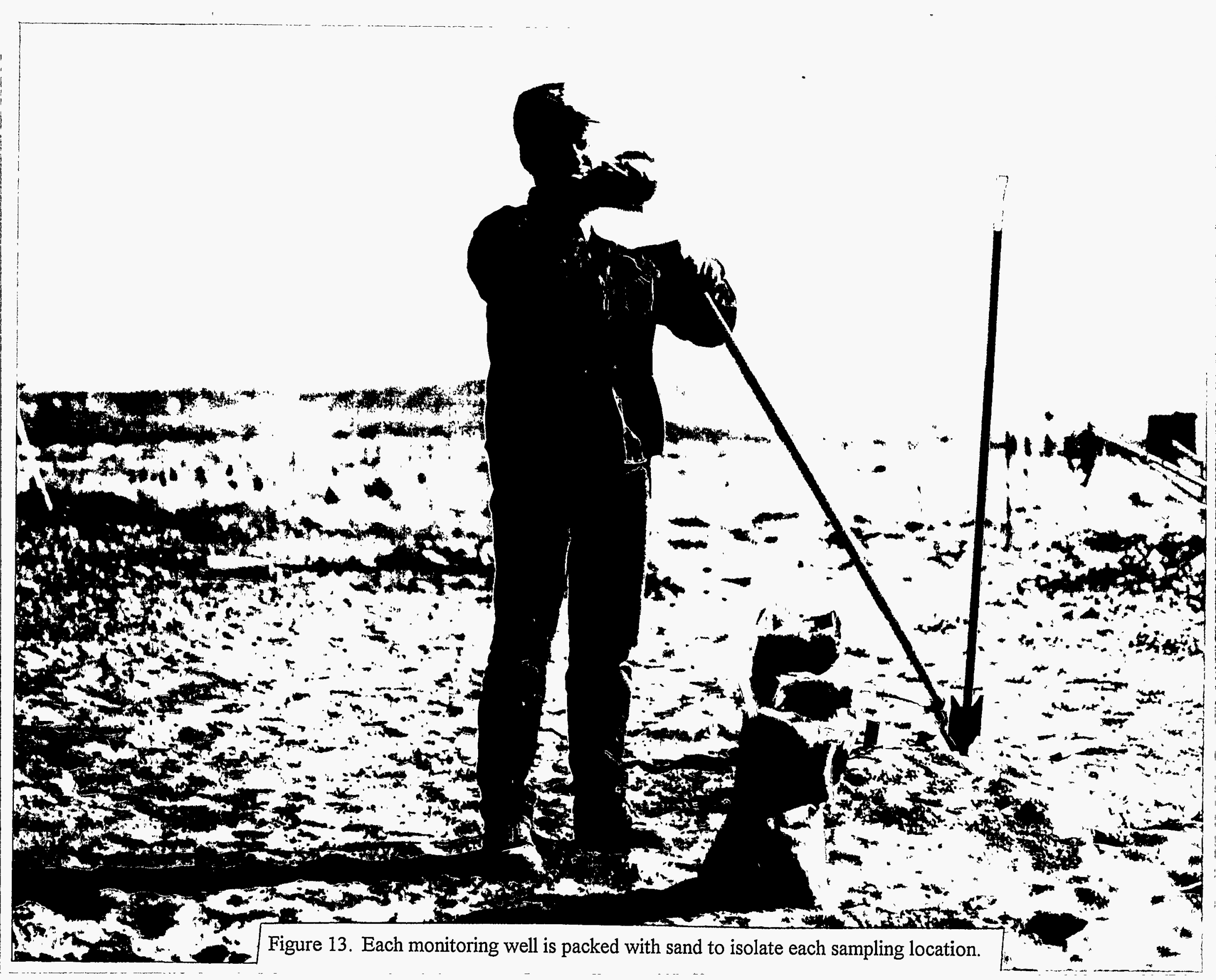



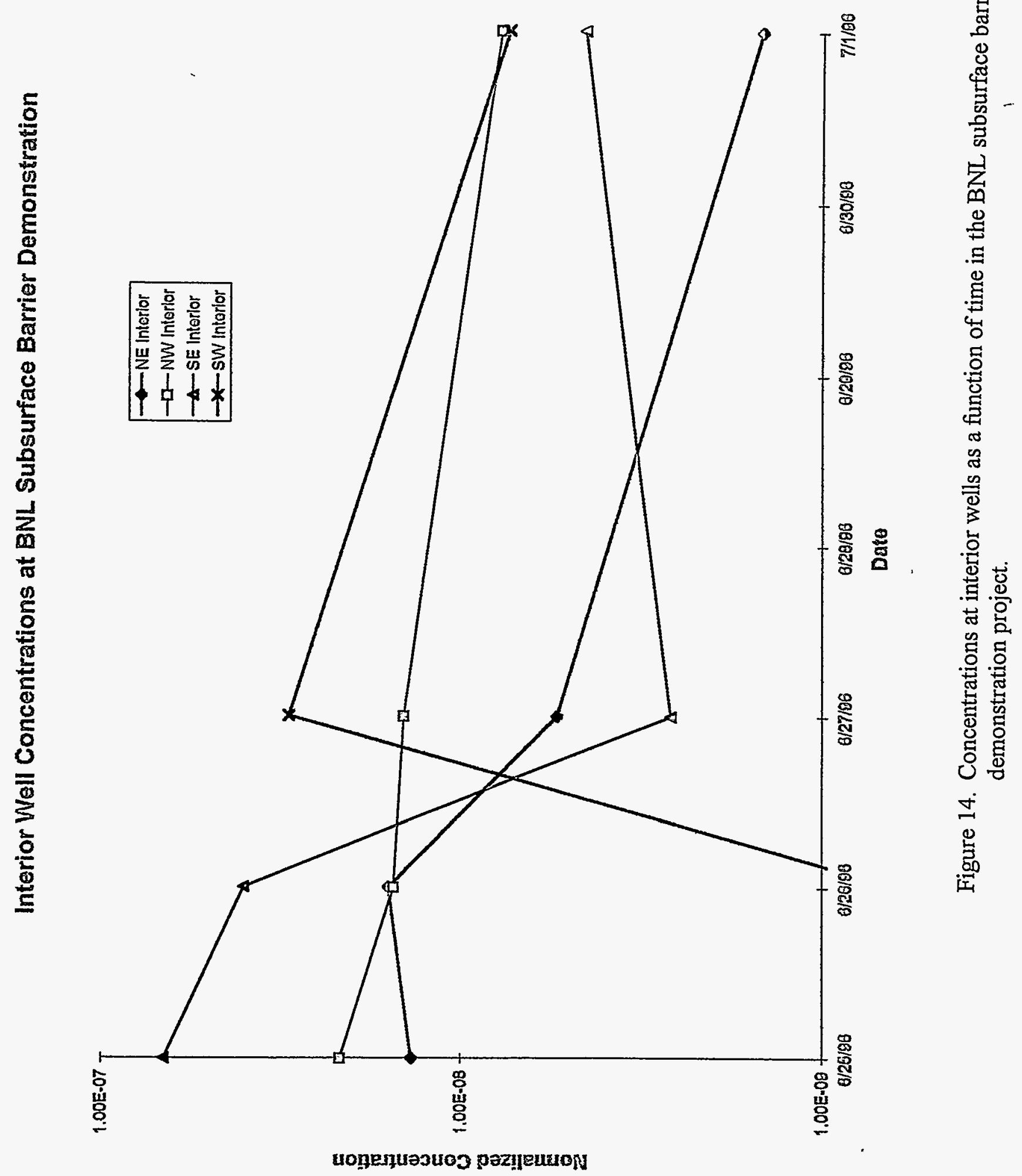


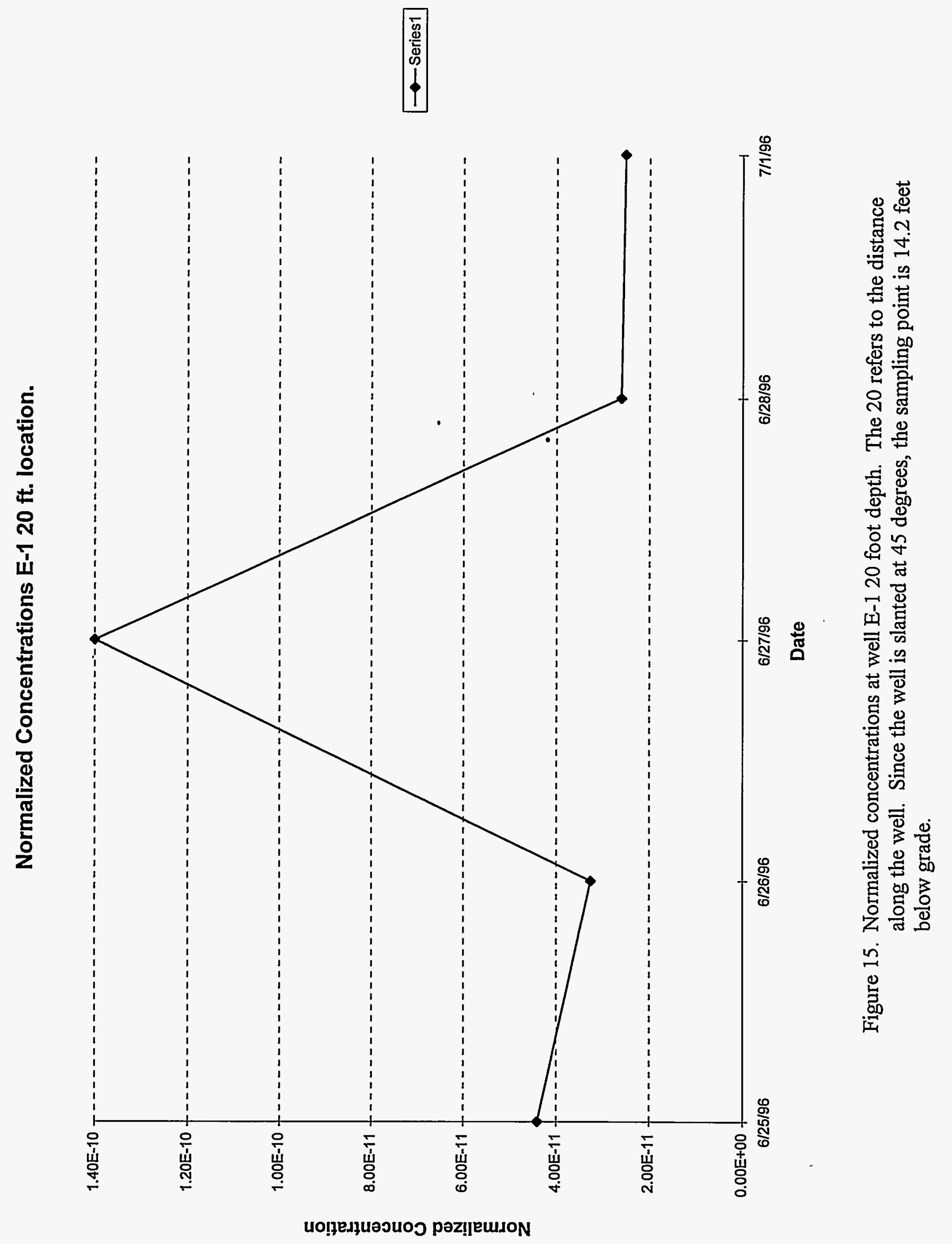

